\title{
Articulos
}

\section{La apicultura: ¿Una alternativa de desarrollo rural sostenible para las laderas secas de Nicaragua?}

\section{Laurent Dietsch}

\section{Recibido: febrero de 2011 / Aceptado: julio de 2011}

Se presenta una investigación participativa enfocada en los actores del sector apícola y sus interacciones, tanto a nivel territorial como de cadenas productivas, en tres zonas de laderas del trópico seco de Nicaragua: Boaco, El Sauce y Ciudad Darío. Utilizando la metodología RAAKS se realizó de manera sucesiva en cada territorio un mapa de actores y cadena de miel, un análisis de innovaciones, una identificación y medición de indicadores locales y una construcción de estrategias territoriales de desarrollo de la apicultura. Cada etapa descansó sobre la recopilación de información secundaria, entrevistas y un taller con los actores relacionados a la apicultura. Se analizaron las principales características e interrelaciones, y de forma general, los rasgos comunes y especificidades de las dinámicas de desarrollo de la apicultura en cada territorio. Se evidencia que el sector productivo apícola está principalmente en manos de pequeños productores y presenta un nivel fuerte de organización. Las organizaciones de apicultores juegan un papel muy importante en el desarrollo de la apicultura en su territorio, articulando diferentes servicios y actores de apoyo, y facilitando a los apicultores el acceso a mercados más remuneradores pero con requerimientos que no podrían cumplir individualmente. Se ha logrado identificar, de forma participativa, en cada territorio, de 4 a 8 innovaciones claves para lograr el "progreso" de la apicultura. Su análisis sirvió de base a la formulación concertada de un conjunto de acciones estratégicas para el desarrollo de la apicultura en cada territorio con sus indicadores y metas.

Palabras clave: Apicultura / territorio / laderas secas / estrategias de desarrollo / innovaciones

* Área de Desarrollo Agrario y Rural, Universidad Centroamericana (UCA-ADAA) correo electrónico:l.dietsch2@gmail.com 


\section{Introducción}

En Nicaragua, las zonas de laderas del trópico seco constituyen una banda de tierra que atraviesa la zona Pacífica de Nicaragua de Noroeste a Sureste (Ilustración 1). Se caracterizan por una estación seca y una estación lluviosa, la predominancia de suelos en pendiente, sometidos a muy fuertes erosiones vinculadas a procesos de deforestación, y una poca disponibilidad de agua. A estas condiciones edafoclimáticas difíciles se agrega un nivel importante de marginalización social y económica de estos territorios: accesibilidad limitada, baja cobertura de servicios básicos (educación, salud...), etc.

Sus poblaciones son principalmente campesinas con sistemas de producción agropecuarios que combinan el cultivo de granos básicos (frijoles, maíz y sorgo) y la crianza de ganadería menor (gallinas, cerdos). Se trata mayoritariamente de una agricultura de subsistencia por diferentes motivos: acceso limitado a la tierra, suelos poco fértiles y frecuentemente agotados por un uso excesivo de productos químicos que limitan los rendimientos, riesgos importantes de pérdidas de cosechas por sequía y durante el almacenamiento. En estas condiciones, la actividad agropecuaria raras veces genera suficientes ingresos a las familias que se mantienen en niveles altos de pobreza. Por otra parte, las oportunidades de empleo en estas zonas son limitadas, con bajos salarios y sin prestaciones sociales. Finalmente, las pocas fuentes de ingresos en estas regiones provocan una migración importante, tanto interna (hacia las ciudades o las zonas de frontera agrícola) como externa (Costa Rica, Estados Unidos, principalmente) (Dietsch, 2002).

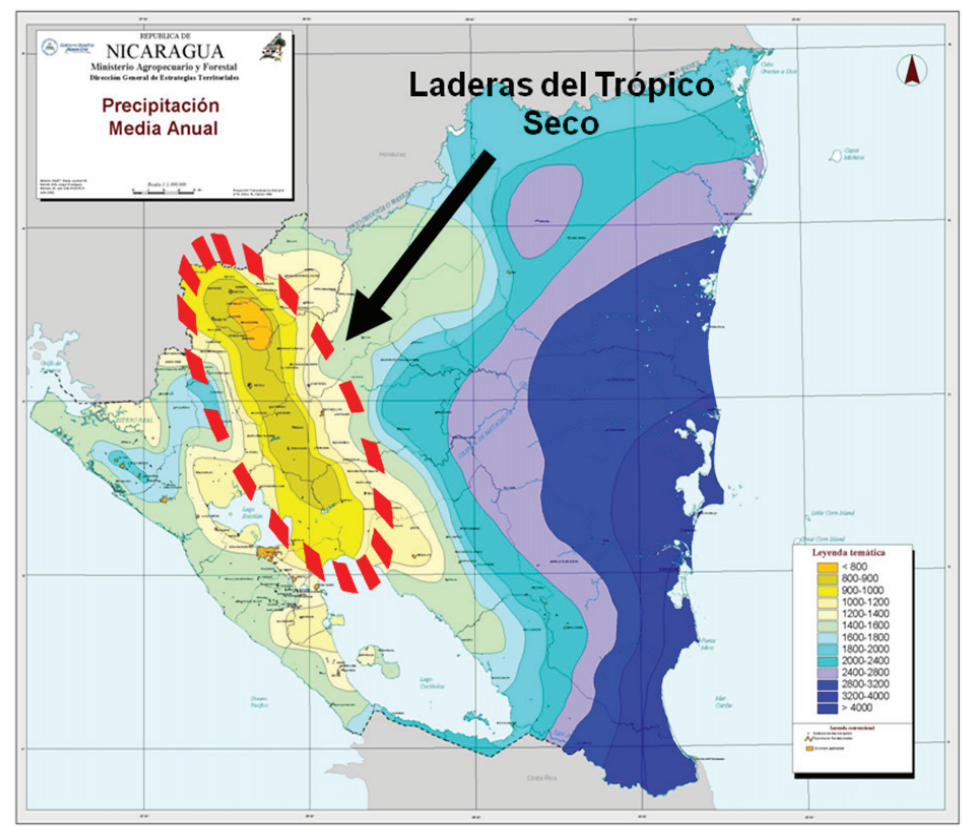

Ilustración 1. Ubicación de las zonas de laderas del trópico seco Fuente: MAGFOR (2006) 
Desde los años 90 se ha dado un aumento significativo de las intervenciones impulsadas por instituciones de desarrollo en estas zonas con el propósito de resolver las problemáticas planteadas. En las acciones impulsadas ha existido generalmente una preocupación por el deterioro ambiental, articulando la búsqueda de alternativas económicas con el rescate y preservación de los recursos naturales. Es en este sentido que el Área de Desarrollo Agrario y Rural de la Universidad Centroamericana (ADAA-UCA,) así como otras organizaciones de desarrollo, han venido realizando esfuerzos desde el año 2000, en torno a la facilitación de procesos de desarrollo, iniciativas e inversiones en la explotación de la apicultura. Han identificado y fomentado esta actividad como un rubro alternativo estratégico para el fomento de un manejo más sostenible de los bosques y para contribuir a favorecer el desarrollo económico en zonas secas de laderas. Su producción se ha visto como factible sin necesitar acceso a grandes extensiones de tierra, relativamente poco vulnerable a los grandes riesgos climáticos en las zonas secas, con externalidades ambientales positivas en zonas tan degradadas y como potencialmente muy interesante desde el punto de vista económico (Dietsch, Ruault \& Touzard, 2008).

En el marco de la línea de investigación "Desarrollo Territorial" de la Agenda de Investigación, Desarrollo e Innovación de la Universidad Centroamericana, el ADAAUCA, en conformidad con sus propias reflexiones y prioridades de investigación (Dietsch et al., 2008) y su deseo de articular sus investigaciones con la promoción del desarrollo por un lado y la formación de profesionales por el otro (Maestría en Desarrollo Rural), se ha planteado centrar su atención en contribuir a mejorar las formas de intervención para acompañar procesos de cambio centrados en los actores. Uno de los campos que está enfocando, y que se relaciona a la problemática de los métodos de intervención para apoyar el desarrollo rural, concierne los procesos de organización de los (pequeños) productores apícolas frente a las evoluciones de los mercados agroalimentarios locales, nacionales o internacionales. En este artículo se presentan los resultados de una primera investigación participativa realizada en este marco, cuyos objetivos fueron los siguientes:

- Realizar un diagnóstico participativo enfocado hacia los actores del sector apícola y sus interacciones tanto a nivel territorial como de cadenas productivas.

- Analizar la diversidad de opciones organizacionales y de estrategias de acceso a mercados de pequeños y medianos productores apícolas en las zonas secas de Nicaragua.

- Analizar las condiciones y medios que han facilitad o dificultado procesos de desarrollo de la apicultura en diferentes territorios del trópico seco de laderas de Nicaragua.

- Formular propuestas concertadas con los actores de acciones estratégicas para el desarrollo de la apicultura en laderas secas de Nicaragua. 


\section{Los fundamentos teóricos del estudio}

\subsection{Los procesos de desarrollo como procesos de aprendizaje producto de las interacciones entre actores}

El punto de partida de esta investigación es considerar las innovaciones o procesos de cambio como procesos de producción de nuevos conocimientos (aprendizaje) por parte de los actores locales enfocados en la resolución de problemas que enfrentan. Partimos de la idea de que los procesos de cambio o de innovación implementados por actores locales no constituyen fines en sí mismos o asuntos de buena voluntad o de dinamismo individual que hacen que una persona sea más apta que otra para realizar cambios o adoptar las propuestas técnico-económicas provenientes de los técnicos y proyectos. Los actores locales realizan cambios en sus prácticas (técnicas, sociales, económicas, organizativas, etc.) cuando aquellas que realizan en la actualidad ya no les satisfacen frente a las situaciones y dificultades que encuentran en sus actividades productivas. Esto implica para ellos "inventar" nuevas formas de hacer las cosas enfocadas en la resolución de problemas que ellos se plantean y para los cuales no hay soluciones definidas de antemano, es decir, procesos propios de reflexión y producción de nuevos conocimientos y por ende, de aprendizaje.

Un factor clave de estos procesos está constituido por las interacciones entre actores sociales. Arce y Long (1988) utilizan la noción de "interfaz" para describir el encuentro efectivo entre individuos o grupos con intereses, recursos y niveles de poder diferentes, y analizar las interacciones tal como se producen concretamente. En diferentes estudios, Darré demuestra que la manera en que los agricultores pueden apropiarse de las propuestas de una intervención de desarrollo depende del tipo de confrontación, de formas y contenido de los debates que se establecen (o no) con los técnicos que les llevan estas propuestas. No se trata de informar, de transmitir un mensaje, de "convencer o concientizar" sino más bien de entender la visión del otro, de cruzar diferentes maneras de ver las cosas. La dinamización de procesos de innovación por actores locales descansa sobre las posibilidades de diálogos internos ("entre pares") y de confrontación de puntos de vista con otros actores (Darré, 1989; 1994).

Esto implica pensar los procesos de cambio o innovaciones como producto de interacciones entre agentes de desarrollo (y sus instituciones), los productores y otros actores locales; como un proceso dinámico de aprendizaje que permite a los actores y a sus organizaciones establecer relaciones de largo plazo, definir metas conjuntas, compartir recursos, colaborar en los procesos y coordinar los planes de trabajo para lograr sus objetivos mancomunados (Guharay, Villar \& González, 2010).

\subsection{El "territorio" y las "cadenas": espacios privilegiados de encuentro entre actores y por ende, de aprendizaje y desarrollo concertado}

La actividad apícola esta "localizada" en ciertos territorios. Las características de estos territorios (ambientales, económicas, sociales, institucionales) presentan condiciones que pueden facilitar o dificultar el desarrollo de actividades como 
la apicultura. A su vez, el desarrollo de una actividad económica tendrá su efecto (positivo o negativo) en la estructuración y dinámica del territorio en su conjunto. Estos procesos son producto de las actuaciones de una serie de actores involucrados directa e indirectamente en la actividad, quienes tienen sus características, roles y relaciones, constituyendo un "sistema de actores" con cierto grado de consolidación y articulación. Fortalecer las interacciones y cohesión de un sistema de actores en el territorio es clave para el desarrollo del mismo (Schetjman \& Berdegué, 2003). Para ello, se debe buscar, con todos los actores involucrados, el hilo conductor que conlleva a un objetivo común alrededor de la apicultura y la construcción de un contrato social que permita el desarrollo del sector. Este enfoque debe permitir conducir a espacios de concertación, consenso y negociación con todos los actores para la construcción de una estrategia de desarrollo apícola acorde con la dinámica del territorio en su conjunto.

La actividad apícola está integrada en "cadenas" que se extienden más allá de los territorios. Estas cadenas están constituidas por el conjunto de actores y actividades estrechamente interrelacionadas, y verticalmente vinculadas a un mismo producto (o productos similares) y cuya finalidad es satisfacer al consumidor (Montigaud, 1992, citado por Chavarría \& Sepúlveda, 2002). El enfoque de cadena permite conducir al análisis de la interrelación entre los actores y factores involucrados directa e indirectamente en los distintos eslabones de la cadena productiva y de valor. A la vez permite la identificación de otros elementos cómo: el nivel de asociatividad existente entre los productores, el nivel de competitividad prevaleciente para poder insertarse en el mercado local o global, y el nivel de compromiso, cooperación y participación que tienen en la autogestión de los procesos locales de desarrollo apícola.

El análisis de cadenas y a nivel de territorio es clave para propiciar la concertación con todos los actores involucrados y lograr formular estrategias de desarrollo integrales sostenibles (social, económica y ambientalmente).

\section{Materiales y métodos: aplicación de la metodología RAAKS enfocada en la consolidación de plataformas de innovación multi-actores en tres territorios específicos representativos}

La metodología RAAKS se enfoca en la consolidación de plataformas de innovación multi-actores. Permite la implementación de una metodología de investigación-acción participativa con herramientas dinámicas que ayudan a fortalecer la comunicación y el trabajo en equipo, y a consolidar espacios locales no sólo de participación sino de procesos colectivos de aprendizaje, ayudando a la construcción de una visión común para la innovación (Engel \& Salomon, 1997).

Se seleccionaron tres territorios representativos de las situaciones existentes de la apicultura en las laderas secas de Nicaragua:

- Zona seca de Boaco: que es un lugar histórico de desarrollo de la apicultura, con una larga trayectoria y diversos actores constituidos alrededor de esta actividad.

- Municipio de El Sauce: en el cual la apicultura tiene un muy alto nivel de 
desarrollo y concentración.

- Municipio de Ciudad Darío: en el cual la actividad apícola es de mucho más reciente desarrollo.

Con un equipo de investigación constituido por diez investigadores ${ }^{1}$ se realizó un proceso paralelo en cada territorio basado en tres etapas:

a) Mapeo de actores y cadena de la miel

b) Análisis de innovaciones e identificación de indicadores locales claves

c) Medición de indicadores locales y construcción de estrategias territoriales de desarrollo de la apicultura.

Cada etapa tuvo como elemento central la realización de un taller con la participación activa de los diferentes actores relacionados a la actividad apícola. Previo al taller se recopiló información primaria y se realizaron entrevistas abiertas con guías de preguntas semi-estructuradas a los actores previamente identificados en la información secundaria. El proceso desembocó en la construcción conjunta y ampliamente participativa de una estrategia de desarrollo para el sector apícola de cada territorio. En el cuadro 1 se presentan los participantes en este proceso:

Cuadro 1. Participantes en el proceso de investigación

\begin{tabular}{l|c|c|c|} 
& El Sauce & Boaco & Ciudad Darío \\
\hline Entrevistas sub estudio 1 & 17 & 20 & 18 \\
\hline Participantes taller 1 & 17 & 27 & 22 \\
\hline Entrevistas sub estudio 2 & 7 & 19 & 9 \\
\hline Participantes taller 2 & 13 & 19 & 18 \\
\hline Entrevistas sub estudio 3 & 5 & 9 & 7 \\
\hline Participantes taller 3 & 14 & 16 & 13 \\
\hline \multirow{2}{*}{$\begin{array}{c}\text { Tipos de actores } \\
\text { participantes en el proceso }\end{array}$} & $\begin{array}{l}\text { Apicultores organizados e individuales, gran } \\
\text { productor individual, transportistas, carpinteros, } \\
\text { pulperas, sastres, comercializadores, ONG } \\
\text { (Asprodic, Swisscontact,..), microfinancieras } \\
\text { (Caruna, FDL, etc.), INTA, MAGFOR, IDR, } \\
\text { CAMIPIME, MINSA, DGI, alcaldías. }\end{array}$ \\
\hline
\end{tabular}

\footnotetext{
Un binomio encargado del proceso en cada territorio constituido por miembros del ADAA-UCA y/o estudiantes de la maestría en desarrollo rural: Ricardo Ruiz y Eddy Trejos en Ciudad Dario, Felix Pavón y Marlon Rojas en Boaco, Elena Peña y Esmilse Obregón en El Sauce; tres asesores en temas de Análisis de cadenas, desarrollo territorial y/o comunicación y procesos multi-actores y docentes de la maestría en desarrollo rural: Falguni Guharay (SIMAS), Selmira Flores (Nitlapan-UCA), Juan Carlos Polvorosa (FCEEUCA) y el autor del artículo como coordinador de la investigación.
} 


\subsection{Realización de sub estudio de mapeo de actores y cadena de la miel en cada territorio}

Esta fase consistió en la realización de un mapeo de los actores relacionados al sector apícola y su funcionamiento en cada territorio, describiendo las principales características y roles que juegan, e identificando los principales flujos de comunicación, cuellos de botella, ventajas, desventajas, bloqueos y retos.

La revisión de información secundaria fue la primera acción de reconocimiento de los actores involucrados en el rubro de la miel. Posteriormente se utilizó como insumo dicha información para la identificación de contactos claves, permitiendo la elaboración de un listado de actores interesantes para ser entrevistados.

Se realizó un total de 55 entrevistas semi-estructuradas (de 17 a 20 por territorio) a la mayor diversidad posible de actores: apicultores organizados e independientes, prestadores de servicios como carpintería, transporte, sastrería, comercializadores, así como a ONG, microfinancieras y sector estatal (IDR, INTA, MAGFOR, MINSA, DGI, alcaldías, etc.).

El procesamiento de la información recolectada sirvió de insumo para la realización en cada territorio de un primer taller, de "mapeo de actores y cadenas de miel" dirigido a los mismos entrevistados. El taller tuvo una duración de entre 4 y 6 horas y fue desarrollado mediante una guía de preguntas orientadoras y generadoras para profundizar sobre las características, roles, prioridades, relaciones, acciones y visión de los actores involucrados. Mediante un proceso de análisis y reflexión se consensuó un mapa de actores del territorio y sus interrelaciones, y se construyó la cadena de la miel. Como base para la preparación de la siguiente etapa, se finalizó con la identificación de las principales innovaciones que se han realizado en el sector apícola en los últimos años o las que están actualmente en proceso.

\subsection{Realización de sub estudio de innovaciones e identificación de indicadores locales}

La segunda etapa consistió en la identificación y análisis, con los actores, de las principales innovaciones realizadas, identificadas en base a su visión de los aspectos claves para el desarrollo de la apicultura en su territorio en sus diferentes dimensiones: condiciones ambientales, producción, transformación-comercialización e institucional-organizacional.

Para esta fase se realizaron 35 entrevistas de profundización a los actores directamente involucrados en las innovaciones identificadas de manera colectiva al final del primer taller. Se utilizó la herramienta Línea de tiempo (sobre los 10 a 20 últimos años) para descubrir los cambios e impacto en los procesos y acciones de innovaciones, identificar quiénes han participado, así como los roles que han venido desempeñando los participantes en los distintos períodos que consideran de relevancia y que han conllevado al avance de la actividad apícola.

El procesamiento de esta información sirvió de insumo al segundo taller (de 13 a 19 participantes por taller), en el cual se analizó la implementación y funcionamiento de cada una de las innovaciones llevadas a cabo, los cambios que se han presentado como resultado y/o consecuencia de dichas innovaciones y sobre 
todo la comunicación, articulación y relaciones entre los distintos actores durante el proceso. Este proceso de reflexión permitió la elaboración de una matriz de relaciones entre actores, logrando identificar claramente los roles y articulaciones correspondientes, sacando aprendizajes y desembocando finalmente en la identificación de indicadores locales claves para el desarrollo de la apicultura.

\subsection{Realización de sub estudio para la construcción participativa de estrategias de desarrollo apícola}

El análisis de la información generada en el segundo taller permitió la identificación preliminar de los indicadores locales de desarrollo de la apicultura en diferentes dimensiones (aspectos tecnológicos, metodológicos y organizacionales). Mediante otra ronda de 21 entrevistas a los actores clave, se validaron y midieron estos indicadores, lo que permitió conocer el punto de partida actual del avance apícola desde los criterios y valoraciones de los actores mismos.

En un tercer y último taller se presentaron y socializaron los resultados de las entrevistas, es decir, el estado actual de los indicadores locales de desarrollo apícola planteados desde cada uno de los actores involucrados. Esta presentación fue la base de una reflexión participativa sobre la visión de futuro de la apicultura en el territorio (metas a nivel de los indicadores formulados y estrategias para alcanzarlas).

\section{Resultados y discusión}

Este proceso de investigación permitió la realización de tres estudios de caso que presentan los resultados detallados de cada territorio: Boaco (Pavón \& Rojas, 2011), El Sauce (Peña \& Obregón, 2011) y Ciudad Darío (Ruiz \& Trejos, 2010). En este artículo se presenta una síntesis de los principales resultados, se reflejan los principales puntos comunes y diferencias entre territorios como base para la obtención de conclusiones globales de la investigación.

\subsection{Mapeo de actores y cadenas vinculados a la apicultura en los tres territorios (resultados del primer sub estudio)}

En cada territorio, en el marco del primer sub estudio, se realizó un mapeo del conjunto de los actores relacionados a la apicultura. Esto permitió identificar a los actores, sus principales características e interrelaciones, y agruparlos en cinco grandes categorías según sus funciones en relación al desarrollo de la actividad apícola:

- Productores de miel: cooperativas, grupos organizados, productores individuales

- Organizaciones y servicios de apoyo a la apicultura (financiamiento, asistencia técnica, etc.)

- Organismos reguladores de la actividad apícola

- $\quad$ Proveedores de materiales, insumos y servicios

- Actores vinculados al proceso de comercialización de la miel

Se evidenció la gran cantidad de actores relacionados con la apicultura y su 
muy alto nivel de presencia directa en los territorios (a nivel municipal), tal como se puede observar en el caso de Ciudad Darío (ilustración 2).

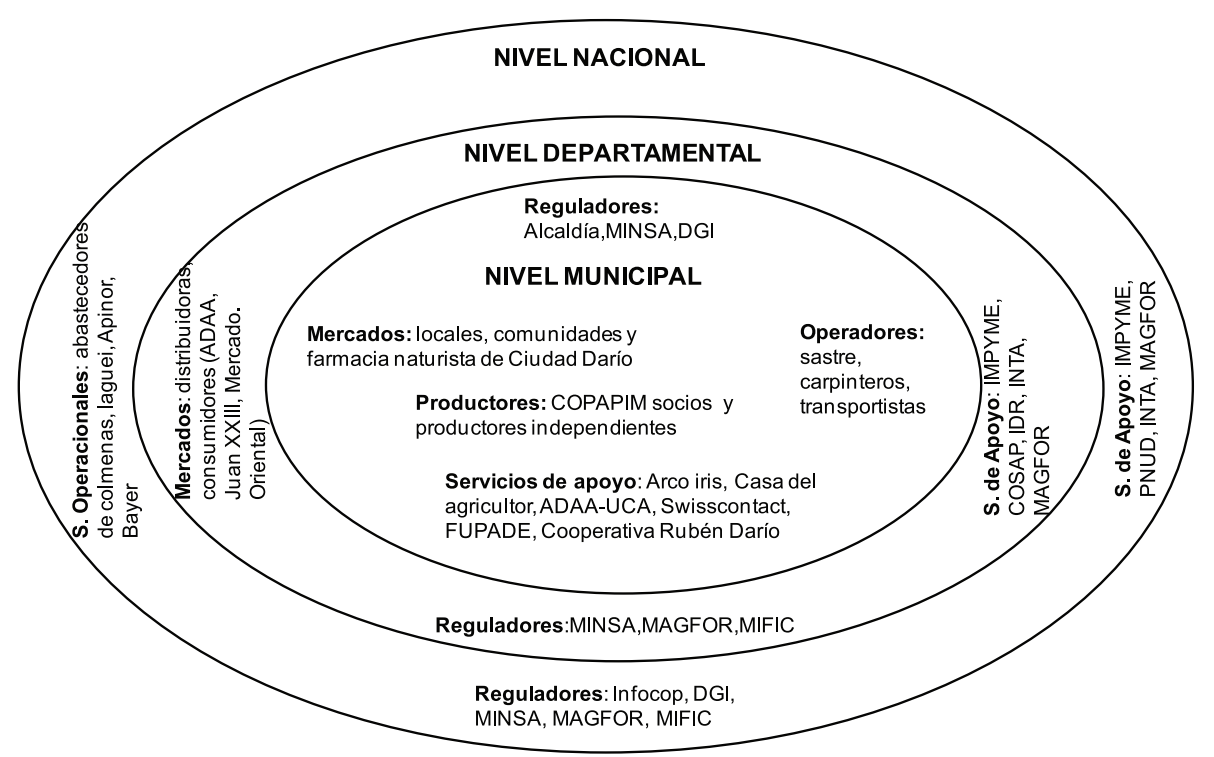

Ilustración 2. Mapeo de actores y su ubicación a nivel territorial (caso de Ciudad Darío)

Fuente: Ruiz y Trejos, (2010)

El análisis del sistema de actores se realizó en un primer momento a nivel territorial y en un segundo momento a nivel de las cadenas productivas, enfatizando las diferentes estrategias y canales de comercialización.

a. Los sistemas de actores vinculados a la apicultura en los territorios

A nivel de la producción, la apicultura esta principalmente en mano de pequeños productores que lo consideran como un rubro de diversificación productiva (cuadro 2). 
Cuadro 2. Los diferentes tipos de apicultores en los territorios

\begin{tabular}{|c|c|c|c|c|c|c|}
\hline $\begin{array}{l}\text { Tipo de } \\
\text { apicultor }\end{array}$ & Características & Boaco & $\begin{array}{c}\text { El } \\
\text { Sauce }^{12}\end{array}$ & $\begin{array}{l}\text { Ciudad } \\
\text { Darío }\end{array}$ & Total & $\%$ \\
\hline $\begin{array}{l}\text { Micro- } \\
\text { apicultores }\end{array}$ & $\begin{array}{l}\quad \text { 1- } 10 \text { colmenas } \\
\text { Muy pocos materiales y } \\
\text { equipos, extracción manual, } \\
\text { no hacen trashumancia, } \\
\text { no todos tienen trajes de } \\
\text { protección ni extractores. }\end{array}$ & 161 & 25 & 16 & 202 & 39 \\
\hline $\begin{array}{l}\text { Pequeños } \\
\text { apicultores }\end{array}$ & $\begin{array}{l}\quad \mathbf{1 0} \text { - } \mathbf{3 0} \text { colmenas } \\
\text { Equipamiento básico } \\
\text { completo, todos con trajes, } \\
\text { acceso a extractores, hacen } \\
\text { trashumancia (El Sauce). }\end{array}$ & 134 & 77 & 10 & 221 & 42 \\
\hline $\begin{array}{l}\text { Medianos } \\
\text { apicultores }\end{array}$ & $\begin{array}{l}\quad \mathbf{3 0} \text { - } \mathbf{6 0} \text { colmenas } \\
\text { Mayor nivel de } \\
\text { equipamiento y manejo } \\
\text { técnico de colmenas - } \\
\text { trashumancia }\end{array}$ & 60 & - & - & 60 & 11 \\
\hline $\begin{array}{l}\text { Grandes } \\
\text { apicultores }\end{array}$ & $\begin{array}{l}\quad \mathbf{6 0}-\mathbf{4 0 0} \text { colmenas } \\
\text { Muy buen equipamiento } \\
\text { y de calidad, medios } \\
\text { de transporte (facilita } \\
\text { trashumancia) }\end{array}$ & 2 & 27 & - & 29 & 7 \\
\hline $\begin{array}{l}\text { Productores } \\
\text { empresarios }\end{array}$ & $\begin{array}{l}\quad \text { + de } 500 \text { Colmenas } \\
\text { Equipos, taller propio de } \\
\text { carpintería, medios de } \\
\text { transporte, equipo de acopio, } \\
\text { procesamiento de la miel }\end{array}$ & 1 & 1 & - & 2 & $\begin{array}{l}\text { Inf. } \\
\text { a } 1\end{array}$ \\
\hline
\end{tabular}

Más del $80 \%$ de los apicultores son pequeños o muy pequeños y se pueden subdividir en dos grupos: 1) los micro-productores, que carecen de infraestructura, equipos y poseen un número reducido de colmenas, no cuentan con extractor, básico para el proceso de producción (extracción de la miel). Sólo algunos tienen trajes de protección, no cuentan con medios de transporte o recursos para realizar trashumancia que es un estrategia clave para el aumento de la producción muy utilizado por los demás apicultores, particularmente en El Sauce, donde la concentración de apicultura es muy alta; 2 ) los pequeños productores, que cuentan generalmente con 10 a 30 colmenas, con un mejor nivel de capitalización en herramientas menores y mayores.

Un poco más del $10 \%$ son medianos productores, ubicados principalmente en Boaco, con un mayor nivel de capitalización (tierra, número de colmenas, equipos, materiales y algunos tienen medio de transporte, etc.) lo que les ha permitido tener

2 En el caso de El Sauce los entrevistados mencionan la existencia de una mayor cantidad de pequeños o micro apicultores no organizados, de los que desconocen la cantidad exacta. 
mayor acceso a créditos. El número de colmenas oscila entre 30-60, poseen medios y equipos para el manejo de los apiarios, aplican un plan de manejo sanitario, son productores con mayor experiencia, algunos de ellos han viajado al extranjero a capacitarse o trabajar en apicultura.

Una minoría son grandes productores, cuentan con medios, equipos y materiales propios y de calidad. El hecho de contar con medios de transporte propio les facilita realizar la trashumancia en los lugares y tiempo adecuados. A pesar de ser el grupo de mayor capitalización, no cuentan con la infraestructura adecuada para el proceso de producción: casetas de extracción de miel y centros de acopio. Por su nivel de experiencia y conocimiento en el manejo de las colmenas, pocos hacen uso de asistencia técnica.

Dos productores empresarios apícolas merecen una clasificación propia, ya que por su importante dinámica productiva cuentan con más de 500 colmenas, poseen tierra propia. Además de equipos, materiales e insumos, poseen su propio taller de carpintería para la construcción de material apícola para uso propio y venta de servicios a productores de la zona. Desarrollan por sí solos las actividades de extracción y exportación, contando con su propia sala de acopio y procesamiento, con capacidad de producir sus propias reinas.

Cabe mencionar que solamente en los territorios de mayor tiempo de presencia de la apicultura se encuentran medianos, grandes productores y empresarios apícolas, cuya actividad económica principal es la apicultura. Pero el $80 \%$ restante son pequeños o medianos productores agropecuarios que combinan sus actividades más tradicionales (granos básicos, hortalizas, etc.) con la apicultura.

El sector productivo presenta un nivel fuerte de organización a nivel local, ya que en los tres territorios la gran mayoría de los productores están organizados (cuadro 3):

- un total de 318 apicultores están organizados formalmente en siete cooperativas

- un total de 161 apicultores pertenecen a ocho grupos informales

Se puede observar una correlación clara entre el grado de organización de los apicultores y el nivel de desarrollo de la actividad apícola. Los apicultores afiliados a cooperativas cuentan globalmente con más colmenas y mejores niveles de rendimientos que los productores pertenecientes a grupos informales o individuales. Solamente los grandes productores, los empresarios apícolas y un grupo de muy pequeños productores en el caso de El Sauce no están organizados.

Estar organizados en grupos o cooperativas permite a los apicultores tener mayor acceso a medios o recursos para realizar trashumancia, a extractores para el proceso de cosecha de miel, a asistencia técnica, a productos para el manejo sanitario de sus colmenas y a la comercialización de sus productos. 
Cuadro 3. Apicultores organizados en cooperativas y grupos no formales

\begin{tabular}{|c|c|c|c|c|c|}
\hline & Territorio & Nombre & $\begin{array}{l}\text { Número de } \\
\text { integrantes }\end{array}$ & $\begin{array}{c}\text { Colmenas por } \\
\text { apicultor/a }\end{array}$ & $\begin{array}{l}\text { Producción } \\
\text { por colmena }\end{array}$ \\
\hline \multirow{8}{*}{ Cooperativas } & El Sauce & $\begin{array}{l}\text { Asociación de } \\
\text { Apicultores de El } \\
\text { Sauce (APIELSA) }\end{array}$ & 27 & 200 & $40 \mathrm{~kg}$ \\
\hline & & Las Flores & 26 & 25 & $30 \mathrm{~kg}$ \\
\hline & & $\begin{array}{l}\text { Asociación de } \\
\text { Cooperativas } \\
\text { Agropecuarias de } \\
\text { El Sauce (UCASA) }\end{array}$ & 20 & 18 & $35 \mathrm{~kg}$ \\
\hline & Boaco & Miel de Bosque & 106 & 30 & $40 \mathrm{~kg}$ \\
\hline & & Miel Dorada & 61 & 5 & $45 \mathrm{~kg}$ \\
\hline & & Encantadora & 45 & 9 & $40 \mathrm{~kg}$ \\
\hline & & Nuevo amanecer & 17 & 30 & $35 \mathrm{~kg}$ \\
\hline & $\begin{array}{l}\text { Ciudad } \\
\text { Darío }\end{array}$ & $\begin{array}{l}\text { (Cooperativa } \\
\text { de Apicultores } \\
\text { de Maunica) } \\
\text { COOPAPIM }\end{array}$ & 16 & 22 & $35 \mathrm{~kg}$ \\
\hline & Total & 7 & 318 & $5-200$ & $35-45 \mathrm{~kg}$ \\
\hline \multirow{9}{*}{$\begin{array}{l}\text { Grupos no } \\
\text { formales }\end{array}$} & El Sauce & Nuevo apicultor & 26 & 15 a 20 & $35 \mathrm{~kg}$ \\
\hline & & San José & 10 & 10 & $30 \mathrm{~kg}$ \\
\hline & & Chemonics & 10 & 5 & $25 \mathrm{~kg}$ \\
\hline & & Mujeres APIELSA & 10 & 5 & $25 \mathrm{~kg}$ \\
\hline & Boaco & Teustepe & 7 & 13.7 & $40 \mathrm{~kg}$ \\
\hline & & Flor de Bosque & 13 & 17 & $25 \mathrm{~kg}$ \\
\hline & & $\begin{array}{l}\text { Mujeres de } \\
\text { Tecolostote }\end{array}$ & 75 & 1.3 & $10 \mathrm{~kg}$ \\
\hline & $\begin{array}{l}\text { Ciudad } \\
\text { Darío }\end{array}$ & 2 grupos de 5 & 10 & 4.4 & $35 \mathrm{~kg}$ \\
\hline & Total & 8 & 161 & 1 a 20 & $10-40 \mathrm{~kg}$ \\
\hline
\end{tabular}

Esta situación refleja que las organizaciones de apicultores juegan un papel muy importante en el desarrollo de la apicultura en su territorio: casi todas de una u otra manera desempeñan cuatro funciones básicas de apoyo al desarrollo de los apicultores, socios pero también no socios (cuadro 4):

- $\quad$ Facilitan el acceso a insumos (alimentos), materiales y equipos proporcionando los contactos con proveedores, negociando precios de compra más favorables, facilitando el traslado de los mismos, financiando el uso de los insumos (a 
pagar con la cosecha) y/o prestando equipos (extractores, salas de extracción, etc.).

- Compran miel para su comercialización de forma directa o para acopiar, fraccionar, envasar y luego vender a diferentes mercados.

- Brindan capacitación y asistencia técnica facilitando el vínculo con técnicos de otras instituciones o realizándolas ellas mismas con sus apicultores más experimentados.

- Gestionan y ejecutan proyectos de cooperación para el desarrollo de la apicultura, lo que les permite acceder a recursos financieros y técnicos requeridos por sus socios y para su propio desarrollo organizacional.

Cuadro 4. Funciones de apoyo a la apicultura desempeñadas por organizaciones apícolas

\begin{tabular}{|c|c|c|c|c|c|c|}
\hline & \multicolumn{3}{|c|}{ El Sauce } & \multicolumn{2}{|c|}{ Boaco } & \multirow{2}{*}{$\begin{array}{l}\text { Ciudad } \\
\text { Darío } \\
\text { COO- } \\
\text { PAPIM }\end{array}$} \\
\hline & UCASA & APIELSA & $\begin{array}{c}\text { Las } \\
\text { Flores }\end{array}$ & $\begin{array}{l}\text { Tierra } \\
\text { Nueva }\end{array}$ & $\begin{array}{l}\text { Encan- } \\
\text { tadora }\end{array}$ & \\
\hline $\begin{array}{l}\text { Facilita el acceso a } \\
\text { insumos (alimentos), } \\
\text { materiales y equipos }\end{array}$ & $\mathrm{x}$ & $\mathrm{x}$ & $\mathrm{x}$ & $\mathrm{x}$ & $\mathrm{x}$ & $\mathrm{x}$ \\
\hline $\begin{array}{l}\text { Compra, acopia y } \\
\text { comercializa miel a } \\
\text { socios y no-socios }\end{array}$ & $\mathrm{x}$ & $\mathrm{x}$ & $\mathrm{x}$ & $\mathrm{x}$ & $\mathrm{x}$ & $\mathrm{x}$ \\
\hline $\begin{array}{l}\text { Facilita capacitación y } \\
\text { asistencia técnica }\end{array}$ & $\mathrm{x}$ & $\mathrm{x}$ & $\mathrm{x}$ & $\mathrm{x}$ & & $\mathrm{x}$ \\
\hline $\begin{array}{l}\text { Gestiona y ejecuta } \\
\text { proyectos de } \\
\text { cooperación para } \\
\text { el desarrollo de la } \\
\text { apicultura }\end{array}$ & $\mathrm{x}$ & & & $\mathrm{x}$ & & $\mathrm{x}$ \\
\hline $\begin{array}{l}\text { Facilita transporte } \\
\text { (colmenas, equipos, } \\
\text { cosecha, etc.) }\end{array}$ & & & & & $\mathrm{x}$ & $\mathrm{x}$ \\
\hline $\begin{array}{l}\text { Financia a los } \\
\text { apicultores }\end{array}$ & $\mathrm{x}$ & & & $\mathrm{x}$ & & \\
\hline Transforma la miel & & & & $\mathrm{x}$ & & $\mathrm{x}$ \\
\hline $\begin{array}{l}\text { Facilita organización } \\
\text { y manejo de apiarios } \\
\text { (colectivos) }\end{array}$ & & & & & & $\mathrm{x}$ \\
\hline
\end{tabular}


Algunas organizaciones juegan funciones adicionales:

- Facilitación de transporte (colmenas, equipos, cosecha, etc.) con medio de transporte propio o facilitando contactos, negociando con transportistas privados.

- $\quad$ Financiamiento a los apicultores con fondos de crédito que han adquirido.

- Transformación de miel para la obtención de valor agregado

- Facilitación de organización y manejo de apiarios (colectivos), en el caso único, de COOPAPIM en Ciudad Darío.

Las funciones que cumplen estas organizaciones las hacen jugar un papel importante de articulación de los diferentes servicios y actores de apoyo a la apicultura, tal como se puede observar en el caso de El sauce (ilustración 3). Sin embargo, cabe mencionar que aunque tienen vínculos con otros actores locales (artesanos, carpinteros, etc.), tienen muy pocos con autoridades locales (alcaldías).

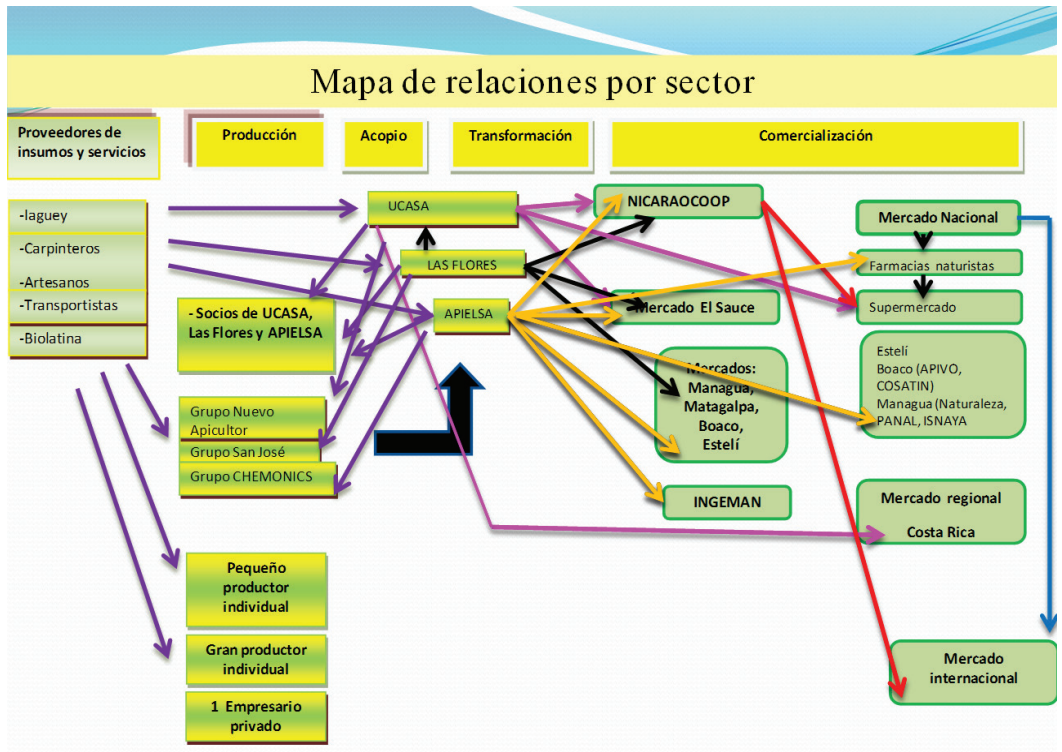

Ilustración 3. Mapa de relaciones por sector en El Sauce

Fuente: Peña y Obregón (2011)

b. Las cadenas apicolas: actores y estrategias de acceso a mercados

El mapeo de las cadenas apícolas en los territorios permitió diferenciar nueve tipos de compradores diferentes de miel con sus distintas características (requerimientos de producto, precios y condiciones de compras) (cuadro 5).

El análisis de estas características ha sido clave para entender las diferentes lógicas y estrategias de comercialización de productores y organizaciones de apicultores, y evidenciar tendencias comunes a los diferentes territorios:

- Los requerimientos superiores de los mercados "de calidad" nacionales (tiendas naturistas, nichos de mercado específicos, supermercados, etc.) así como de los mercados de exportación, hacen que no sean accesibles de forma directa 
para los micro, pequeños y medianos apicultores, sea por requerimientos de calidad y presentación, sea por los volúmenes de compra o requerimientos de permisos de exportación. Las organizaciones de productores son clave para facilitar el acceso a este tipo de mercados. Una empresa extranjera que se instaló recientemente en el país (Empresa Ingeman) ha venido a jugar un papel en la exportación.

- Los apicultores aprovechan fundamentalmente dos opciones de comercialización, generalmente de forma combinada:

- mercados tradicionales, principalmente locales (comunitarios o municipales) y algunas veces nacionales (mercados tradicionales capitalinos o de cabeceras departamentales).

- venta a las cooperativas (de las cuales son socios, pero no necesariamente), las que facilitan el acceso a los demás compradores, sea fraccionando, etiquetando yempacando la miel (COOPAPIM, UCASA), sea simplemente facilitando procesos de acopio-comercialización y/o certificación (Tierra Nueva, la Encantadora, Las Flores, APIELSA).

- La estrategia generalmente utilizada por los productores es quedarse con una pequeña parte de su producción para la venta local directa, la cual les funciona como una "alcancía" permitiéndoles vender su producto a lo largo del año en función de oportunidades o necesidades. La cantidad guardada para la venta directa depende también de los precios relativos y formas de pago que les ofrecen las cooperativas, de sus capacidades de compra y del grado de "saturación del mercado local". Por otro lado, vender a cooperativas locales les permite a los apicultores, además de un canal de comercialización, la posibilidad de acceder a los demás servicios de apoyo que facilitan. 
Cuadro 5. Diferentes compradores de miel y sus características

\begin{tabular}{|c|c|c|c|c|}
\hline \multicolumn{2}{|c|}{ Compradores } & Requerimiento & $\begin{array}{l}\text { Precio de } \\
\text { compra }\end{array}$ & $\begin{array}{c}\text { Condiciones de } \\
\text { compra }\end{array}$ \\
\hline \multicolumn{2}{|c|}{$\begin{array}{l}\text { Comunitario-municipal } \\
\text { (consumidores locales) }\end{array}$} & $\begin{array}{l}\text { Pocos; venta miel } \\
\text { en frascos sin } \\
\text { etiqueta o con }\end{array}$ & \begin{tabular}{|l|} 
Boaco $(\$ 2.16)$ \\
El Sauce $(\$ 2.5)$ \\
Ciudad Darío
\end{tabular} & $\begin{array}{l}\text { Pago de contado } \\
\text { o se deja en } \\
\text { depósito en }\end{array}$ \\
\hline \multicolumn{2}{|c|}{$\begin{array}{l}\text { Mercados tradicionales } \\
\text { departamentales o } \\
\text { nacionales (comerciantes } \\
\text { de mercados) }\end{array}$} & etiqueta rústica & $(\$ 1.4)$ & puntos de venta \\
\hline \multirow{4}{*}{$\begin{array}{l}\text { Cooperativas } \\
\text { apícolas } \\
\text { locales: }\end{array}$} & COOPAPIM & Granel & $\$ 1.4$ & Contado \\
\hline & \begin{tabular}{|l} 
Las Flores \\
APIELSA \\
UCASA \\
\end{tabular} & Granel & $\begin{array}{l}\$ 1.9(+0.016 \text { si } \\
\text { es certificada })\end{array}$ & Contado \\
\hline & Tierra Nueva & Granel & $\begin{array}{l}\$ 2 \text { a } \$ 2.16 \\
\text { (según calidad) }\end{array}$ & $\begin{array}{l}50 \% \text { a la entrega } \\
\text { y } 50 \% \text { a los } 30- \\
60 \text { días }\end{array}$ \\
\hline & Encantadora & Granel & $\$ 2.16$ & Contado \\
\hline \multicolumn{2}{|c|}{ NICARAOCOOP } & $\begin{array}{l}\text { Granel - miel } \\
\text { certificada }\end{array}$ & $\$ 2.5$ & $\begin{array}{l}\text { Contado a } \\
\text { cooperativas }\end{array}$ \\
\hline \multicolumn{2}{|c|}{$\begin{array}{l}\text { Nichos de mercado en } \\
\text { Managua (empresas, } \\
\text { hoteles...) }\end{array}$} & $\begin{array}{l}\text { Etiqueta de } \\
\text { calidad, } \\
\text { pequeña } \\
\text { presentación }\end{array}$ & $\begin{array}{l}\text { Ciudad Darío } \\
(\$ 2.6)\end{array}$ & \\
\hline \multicolumn{2}{|c|}{ Tiendas naturistas } & \begin{tabular}{|l} 
Etiqueta de \\
calidad, pequeñas \\
presentaciones \\
(certificación) \\
- miel y otros \\
subproductos
\end{tabular} & $\begin{array}{l}\begin{array}{l}\text { Boaco } \$ 4 / \mathrm{kg} \\
\text { (indiv.) }\end{array} \\
\text { Ciudad Darío: } \\
\$ 2.6 / \mathrm{kg}\end{array}$ & Pago de contado \\
\hline \multicolumn{2}{|c|}{ Supermercados } & $\begin{array}{l}\text { Idem. tiendas más } \\
\text { código de barra } \\
\text { más constancia en } \\
\text { entrega }\end{array}$ & $\begin{array}{l}\$ 5 \text { al } \\
\text { consumidor } \\
\$ 3.5 \text { al } \\
\text { proveedor }\end{array}$ & \\
\hline \multicolumn{2}{|c|}{$\begin{array}{l}\text { Internacional, mercado de } \\
\text { calidad (orgánico, comercio } \\
\text { justo...) }\end{array}$} & $\begin{array}{l}\text { Certificación - } \\
\text { por barril }\end{array}$ & $\begin{array}{l}\$ 3.3 / \mathrm{kg} \\
\text { (vendido por } \\
\text { Tierra Nueva) }\end{array}$ & $\begin{array}{l}50 \% \text { a la entrega } \\
\text { y el restante al } \\
\text { mes o a los dos } \\
\text { meses }\end{array}$ \\
\hline \multicolumn{2}{|c|}{$\begin{array}{l}\text { Internacional (mercado } \\
\text { convencional) - Ingeman }\end{array}$} & $\begin{array}{l}\text { Cumplir estándar } \\
\text { básico de calidad } \\
\text { - por barril } \\
\end{array}$ & $\begin{array}{l}\$ 2 \text { a } \$ 2.33 / \\
\text { kg pagado por } \\
\text { Ingeman }\end{array}$ & $\begin{array}{l}\text { Pago a través de } \\
\text { CK }\end{array}$ \\
\hline
\end{tabular}


Cada territorio presenta sus especificidades:

- En el caso de Boaco (ilustración 4), el mercado local, en particular en la cabecera departamental, tiende a saturarse rápidamente, por lo cual los socios de varias cooperativas entregan la totalidad de su producción a la misma. No es así de los grupos y cooperativas ubicados en otros municipios (Teustepe, Tecolostote, Santa Lucía). Dos cooperativas (Tierra Nueva y La Encantadora) articulan los procesos de comercialización comprando directamente a socios de las demás cooperativas y grupos no formales que juegan un papel muy limitado en este proceso. Tierra Nueva, de mayor trayectoria en el territorio y con licencia de exportación, es la que comercializa la mayor parte de la miel del territorio e inclusive de otros territorios (Occidente). Sin embargo, La Encantadora va ganando espacio, ofreciendo mejores condiciones de compra (al contado, sin aplicar "castigos" a nivel de precio por la calidad de la miel) pero se ve limitada por su capacidad financiera. Las débiles capacidades de extracción, acopio y fraccionamiento de producción, hacen que muy poco se aprovechen los mercados nacionales "de calidad". La mayor parte de la miel se dirige a la exportación a través de Tierra Nueva o de Ingeman. Los grandes productores cuentan con sus propios canales de comercialización directa.

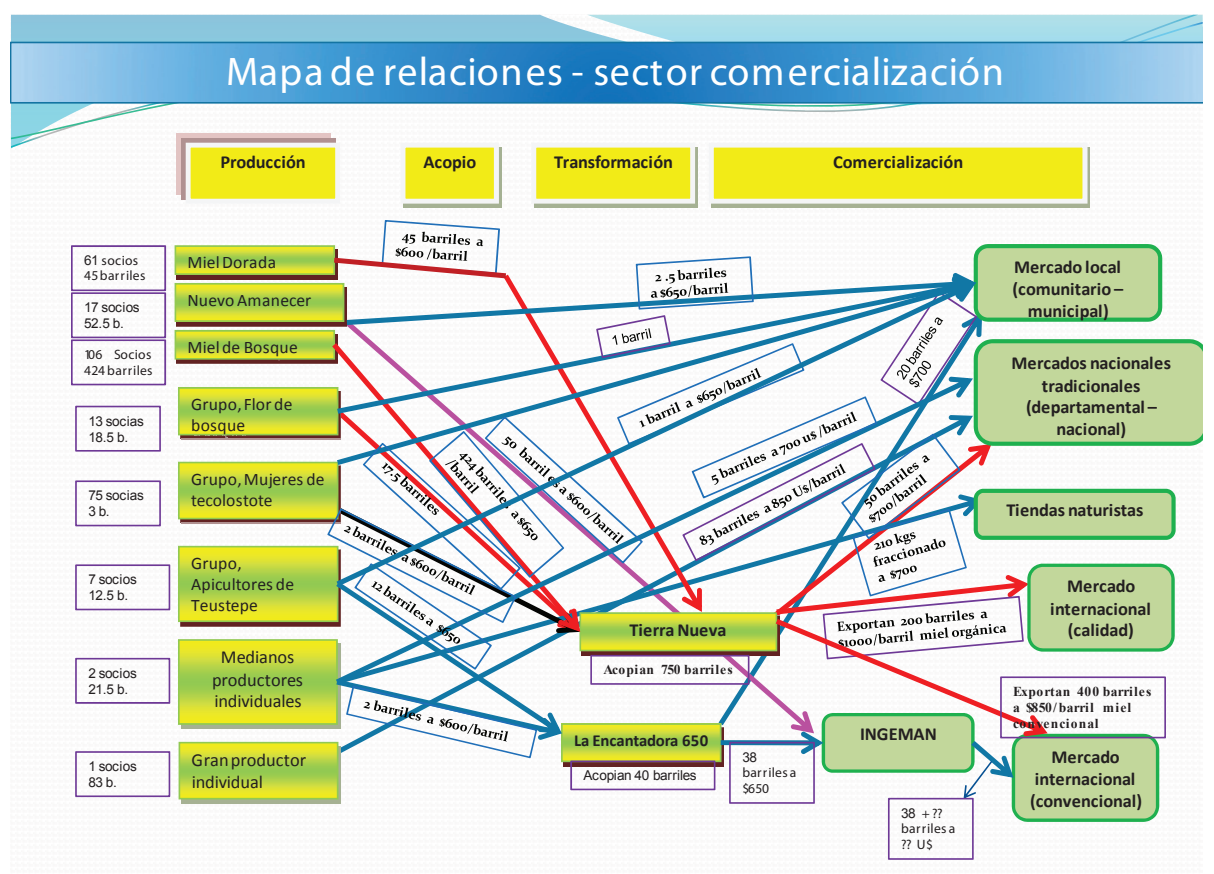

Ilustración 4. Actores y rutas de comercialización de miel en Boaco Fuente: Pavón y Rojas (2011).

En el caso de El Sauce (ilustración 5), el mercado local presenta la característica de ofrecer mejores precios que las cooperativas, por lo que guardar un $10-15 \%$ de la producción para la venta local es una práctica generalizada. En este territorio, la comercializadora NICARAOCOOP juega un papel muy importante 
de intermediación entre las cooperativas locales y el acceso a mercados nacionales de calidad (tiendas, supermercados) e internacionales de miel certificada. En este proceso, como prioridad institucional, prioriza las cooperativas de pequeños apicultores (Las Flores y UCASA). APIELSA por ser una cooperativa de medianos apicultores ha estado vendiendo la mayor parte de su producción a Ingeman. Cabe mencionar finalmente que UCASA ha estado desarrollando su propia capacidad de fraccionamiento, etiquetado y venta al detalle, por lo cual se está abriendo canales directos de venta hacia mercados nacionales de calidad.

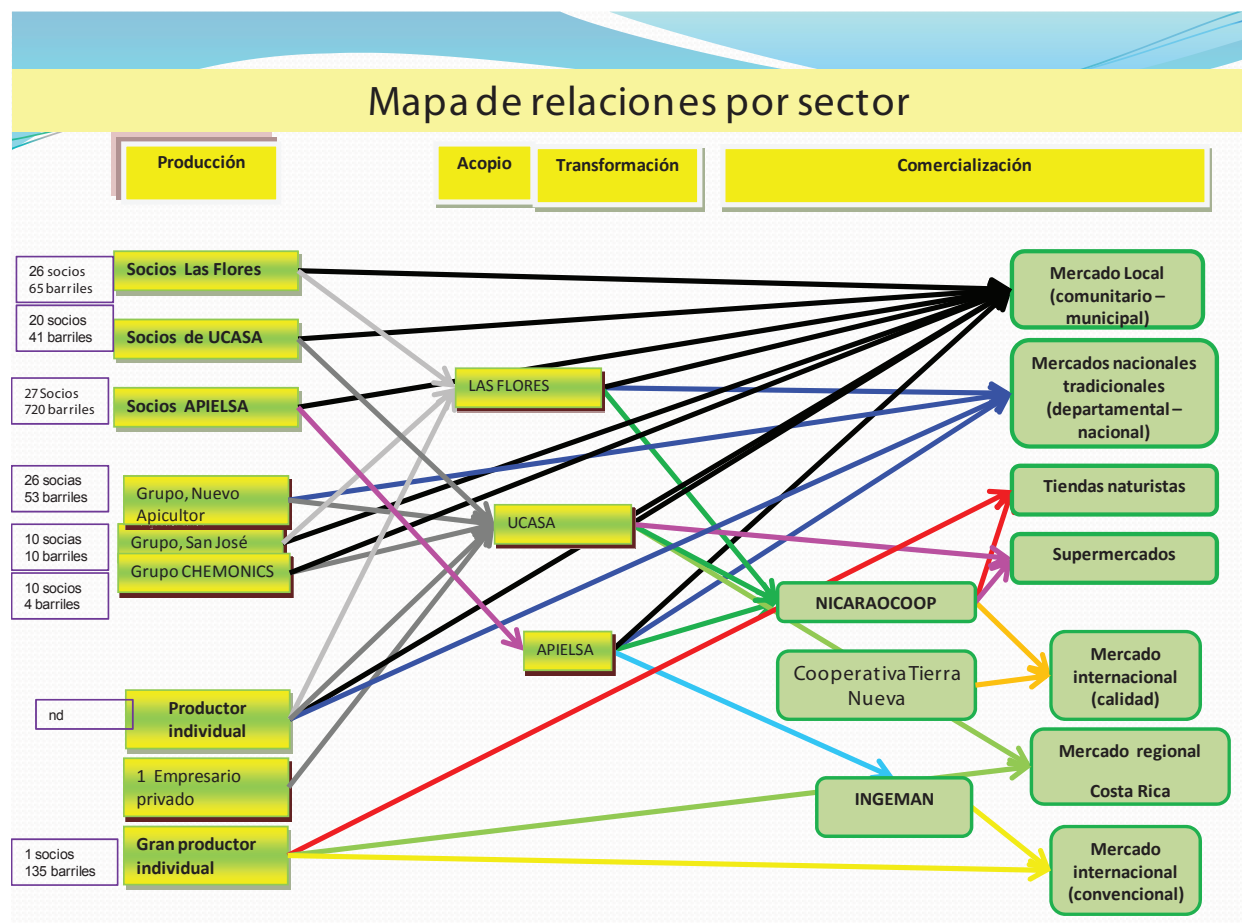

Ilustración 5. Actores y rutas de comercialización de miel en El Sauce Fuente: Peña y Obregón (2011).

En el caso de Ciudad Darío (Ilustración 6), la COOPAPIM, única cooperativa apícola, presenta la particularidad de manejar un apiario colectivo aparte de las colmenas que sus socios poseen individualmente. Ha desarrollado capacidades de almacenamiento, fraccionamiento, etiquetado, de miel y también de elaboración de sub productos (polen, propóleos) que le permite acceder a mercados de calidad en Managua. Lo hace sea directamente hacia tiendas naturistas o a través de una agente de venta (pagada por comisión) hacia determinados nichos de mercado (hoteles, grandes empresas, restaurantes, etc.). Su principal limitación es su capacidad financiera que no le permite procesar mucho más que la producción del apiario colectivo. La producción individual se vende al mercado local a precios netamente más bajos que en los mercados locales de los demás territorios. 


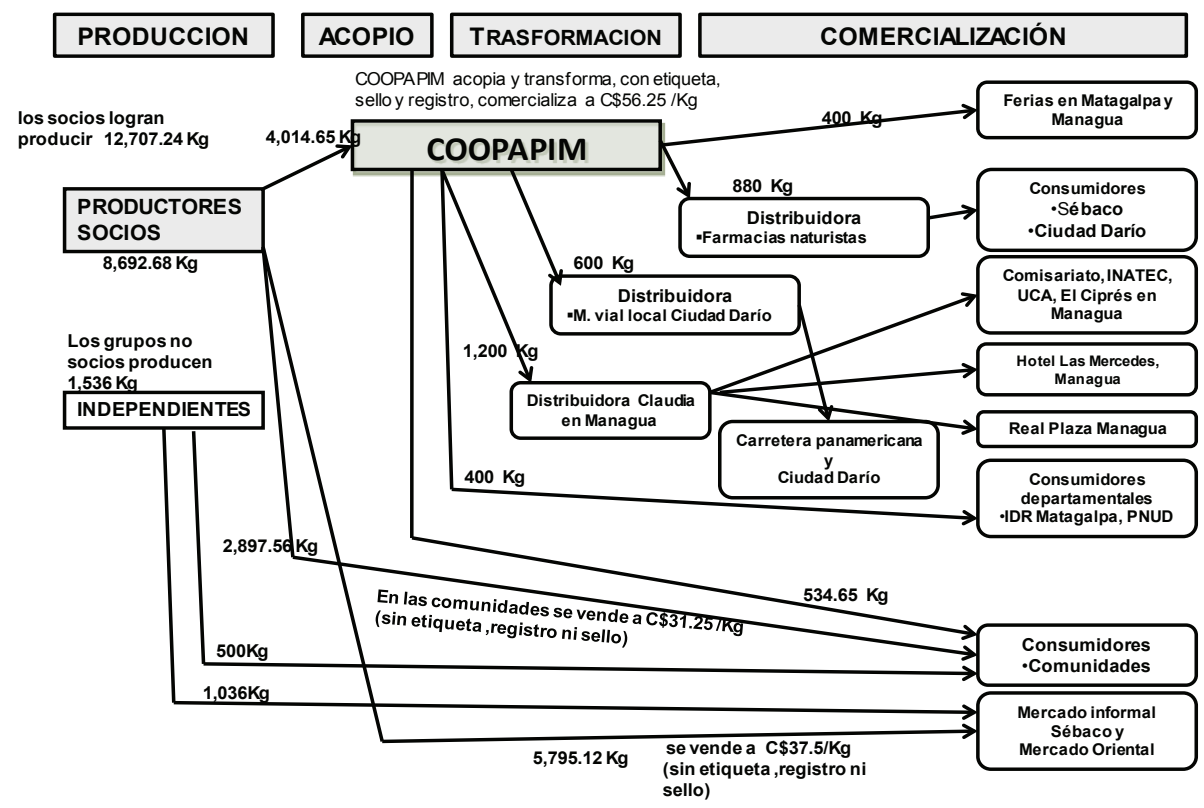

Ilustración 6. Actores y rutas de comercialización de miel en Ciudad Darío Fuente: Ruiz y Trejos (2010).

3.2. Las innovaciones claves para el desarrollo de la apicultura en el territorio: actores y procesos (resultados del 2 do sub estudio)

a. El arranque y desarrollo de la apicultura en los territorios (desde las líneas de tiempo)

- La apicultura se desarrolla en Boaco y luego en El Sauce en los años 80 con el apoyo del gobierno

Si bien es cierto, se mencionan algunas iniciativas privadas de implementación de la apicultura en los años 50, esta actividad realmente empieza a tomar fuerza en la zona de Boaco y El Sauce en los 80 con el apoyo del gobierno. A través del Programa Nacional Apícola, cuyos impulsores eran el Ministerio de Agricultura y Reforma Agraria, CARE-Canadá y el Banco nacional de desarrollo (BND), que tenía por objetivo diversificar la producción campesina, nacen en los 80 las primeras asociaciones locales de apicultores.

En 1987 se crea el Centro Apícola Nicaragüense de Desarrollo (CAND) que comercializaba el producto entregado por los apicultores a través de las asociaciones; daba dos cursos de capacitación por año llegando a egresar un promedio de 40 nuevos productores; abastecía de materiales y equipo apícola a través de las asociaciones regionales; brindaba asistencia técnica. Con este esfuerzo, se logró consolidar un sector apícola de alrededor de 400 apicultores, principalmente concentrados en 


\section{Boaco y León (El Sauce).}

En Ciudad Darío se habían involucrado algunos carpinteros para el proceso de construcción de colmenas, pero no lograron un adecuado establecimiento de los apiarios, que fueron objeto de hurto, saqueo y quemas, provocando desinterés en la actividad en ese momento.

\section{- $\quad$ Crisis del sector en los 90}

Para 1990, con el cambio de gobierno y la implementación de políticas de ajuste estructural, se detiene bruscamente el apoyo público al desarrollo apícola. Incluso la propiedad donde estaba ubicado el CAND se regresa a sus antiguos dueños. Como consecuencia directa, se desarticula el sector apícola a nivel nacional.

Esfuerzos aislados de algunas organizaciones no gubernamentales intentaron dar continuidad a la promoción del desarrollo apícola en dos grandes ejes principales:

- Apoyo-consolidación de organizaciones de apicultores ya constituidas. Oxfam-Bélgica, logra abrirles espacios en la exportación al mercado justo. Apoyó la creación de una entidad que asumiera el liderazgo y representación ante los productores -Fomento y Comercializadora Apícola Nicaragüense, S.A. (FOCANICSA)- con dos organizaciones miembros: la Cooperativa Agropecuaria de Producción y Desarrollo Apícola (CODAPI) y la Asociación de Apicultores de Boaco (APIBO). FOCANICSA se convirtió en el brazo comercializador de estas organizaciones durante los siguientes cuatro años, encargándose de establecer los contactos, negociar y garantizar el acopio y pago a los productores. Se logra la certificación como productores de miel orgánica por parte de la CCPB de Italia, para un pequeño grupo de 28 productores certificados (INPYME, 2005). Igualmente, en el sector de El Sauce, proyectos de desarrollo (Proyecto Manuel López") siguen consolidando y ampliando la apicultura en el municipio.

- El fomento de nuevas iniciativas de apicultura. Se destaca la ONG Cantera (apoyada por Trocaire), que ha retomado la iniciativa de organizar una escuela de apicultura para la formación de nuevos apicultores entregando a los egresados equipos y materiales básicos que les permiten arrancar con esta actividad productiva, principalmente en Mateare y Belén (Rivas). Este esfuerzo fue retomado y 'aprovechado' por otras organizaciones (ADAAUCA, Acción contra el Hambre, ACTED, entre otras) para abrir nuevos 'focos' de desarrollo de la apicultura como en Ciudad Darío a finales de los 90. Es así que un grupo de productores de la cuenca de Maunica (12 personas), apoyados por ADAA-UCA, reciben las primeras capacitaciones y pasan inmediatamente a manejar un pequeño apiario.

Estos esfuerzos sentaron las bases de un desarrollo más fuerte del sector y auge de la actividad apícola en los años 2000. 


\section{- Nuevo despegue de la apicultura en los años 2000}

Las cifras que se presentan aun con sus diferencias e incertidumbres muestran claramente una tendencia al crecimiento rápido del sector en los años 2000. Según Garibay y Zamora (2003), para el ciclo 2002-2003, había en el país un total de 5,187 apiarios atendidos por 132 apicultores. Según datos del Ministerio Agropecuario y Forestal (MAGFOR, 2006), en el 2006 existían aproximadamente 22,656 colmenas y 980 apicultores. Finalmente, de acuerdo con los últimos datos manejados por el MAGFOR, se estima que para el 2008 en Nicaragua existían alrededor de 23,000 colmenas atendidas por unos 1,200 apicultores.

- Los talleres realizados en los tres territorios en el marco del 2 do sub estudio de la investigación, evidenciaron que este crecimiento ha sido posible por el apoyo significativo tanto de la cooperación al desarrollo a través del impulso de proyectos de desarrollo con componentes de apicultura en los diferentes territorios (UE, IIZ, etc.), como de instituciones públicas (IDR, INPYME, etc.). Se identificaron los siguientes aspectos claves en el apoyo brindado al desarrollo del sector:

- Asistencia técnica y capacitación para aprender y/o mejorar el manejo técnico de la apicultura: renovación y crianza de reinas, sistemas de alimentación, trashumancia, control de Varroa, etc.

- Inversiones en mejoramiento de equipamientos e infraestructuras, centros de acopio, mejora de calidad de los equipos (extractores de acero inoxidable, etc.).

- Fortalecimiento organizativo de grupos de apicultores: legalización de nuevas cooperativas, constitución de grupos nuevos.

- Gestión de recursos económicos canalizados a través del sector microfinanciero (CARUNA, FDL, FUDEMI, ACODEP y Fundación José Nieborowsky) mediante la apertura de líneas de crédito para la apicultura.

- Apoyo a iniciativas de transformación y generación de valor agregado, de certificación, etc.

Si bien es cierto que estos procesos permitieron un crecimiento del número de apicultores y de colmenas y por ende de los volúmenes de producción apícola en los tres territorios con la creación de muchas capacidades locales, no están exentos de limitaciones o dificultades, algunas transversales a todos los territorios (aparición de nuevas plagas como la Varroa), y otras específicas a la dinámica de cada territorio:

En El Sauce se da una saturación del espacio por el aumento de la cantidad de apicultores y colmenas, obligándolos a implementar la práctica de trashumancia sobre distancias más largas y por ende con costos más altos que disminuyen la rentabilidad de la actividad, tanto más que a pesar de esta práctica los rendimientos han bajado (de más de $50 \mathrm{~kg} /$ colmena hasta niveles promedios actuales de 25-35) (ilustración 7). 


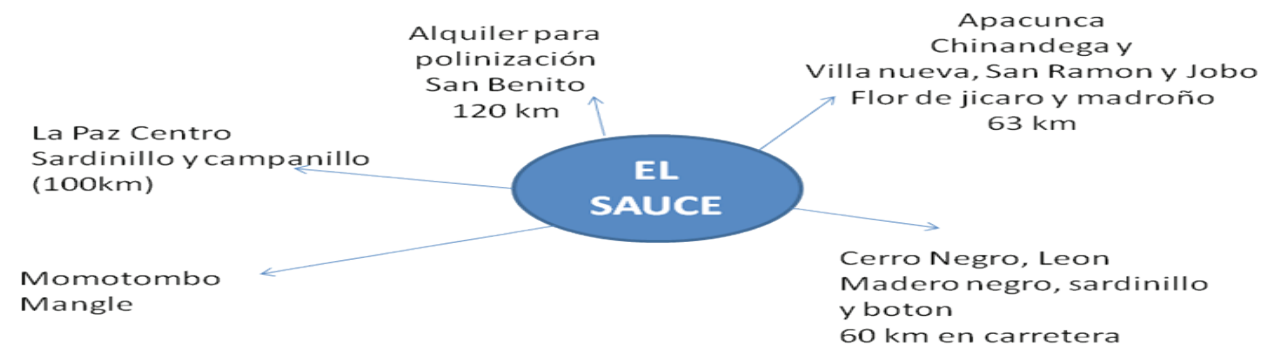

Costo de transporte: traslado de 25 a 30 colmenas $=C \$ 1,100$

Ilustración 7. Lugares de trashumancia de los apicultores de El Sauce Fuente: Peña y Obregón (2011)

En Boaco el aumento de la apicultura consistió en gran parte en el crecimiento de la cantidad de pequeños apicultores sin equipamiento necesario, dándose una disminución de rendimientos y de calidad de la miel (productores mencionan que tenían antes hasta $80 \mathrm{~kg}$ de miel por colmena). Esta disminución se acentuó por la degradación ambiental, vinculada en particular al crecimiento de la ganadería (degradación de bosques, fuertes quemas, etc.). Así mismo, la principal organización de apicultores del territorio (APIBO) entró en crisis en los 90, provocando una desarticulación del sector entre los nuevos grupos derivados (Nuevo Amanecer, Miel Dorada, Tierra Nueva...).

En Ciudad Darío, a pesar de ser la apicultura una actividad reciente, se ha logrado fortalecer capacidades técnicas, organizativas y administrativas pero a una escala muy reducida y aún insuficiente para que tenga un peso real en la dinámica del territorio, principalmente por falta de recursos financieros para dar saltos en el territorio.

\section{b. Las innovaciones claves, actores y aprendizajes (según los actores locales)}

En base al análisis de la evolución de la apicultura en su territorio, se pidió a los participantes del 2 do taller plantear los elementos que según ellos eran claves para el "progreso" de la apicultura en su territorio (cuadro 6). 
Cuadro 6. Elementos claves para el desarrollo según los actores locales

\begin{tabular}{|c|c|c|c|c|}
\hline Sectores & & Boaco & El Sauce & $\begin{array}{c}\text { Ciudad } \\
\text { Darío }\end{array}$ \\
\hline \multirow[t]{2}{*}{ Ambiental } & $\begin{array}{l}\text { Tener mejores condiciones ambientales } \\
\text { (reforestación con especies meliferas, } \\
\text { regeneración natural, quemas controladas, } \\
\text { reducción del despale y la aplicación de } \\
\text { agroquímicos) } \\
\end{array}$ & & $\mathrm{X}$ & \\
\hline & $\begin{array}{l}\text { Promoción integral de planes de manejo de } \\
\text { finca para la apicultura con reforestación } \\
\text { con especies meliferas }\end{array}$ & & $\mathrm{X}$ & $\mathrm{X}$ \\
\hline \multirow{6}{*}{ Producción } & $\begin{array}{l}\text { Integrar jóvenes y productores a la actividad } \\
\text { apícola }\end{array}$ & & & $\mathrm{X}$ \\
\hline & $\begin{array}{l}\text { Ampliar el número de colmenas por } \\
\text { productor }\end{array}$ & $\mathrm{X}$ & & $\mathrm{X}$ \\
\hline & $\begin{array}{l}\text { Elevar la productividad de las colmenas } \\
\text { (producción/colmena) }\end{array}$ & $\mathrm{X}$ & $\mathrm{X}$ & $\bar{X}$ \\
\hline & Mejorar el manejo técnico de los apiarios & $\mathrm{X}$ & $\mathrm{X}$ & \\
\hline & Diversificar la producción apícola & & $\mathrm{X}$ & \\
\hline & $\begin{array}{l}\text { Mejorar los ingresos económicos de las } \\
\text { familias apicultoras y sus condiciones de } \\
\text { vida }\end{array}$ & $\mathrm{X}$ & $\mathrm{X}$ & \\
\hline \multirow{5}{*}{$\begin{array}{l}\text { Procesamiento, } \\
\text { comercialización } \\
\text { y consumo de la } \\
\text { miel }\end{array}$} & $\begin{array}{l}\text { Mejorar la calidad de la miel (y el control de } \\
\text { la calidad) }\end{array}$ & $\mathrm{X}$ & $\mathrm{X}$ & \\
\hline & $\begin{array}{l}\text { Ampliar y mejorar la transformación y } \\
\text { fraccionamiento de la miel }\end{array}$ & $\mathrm{X}$ & $\mathrm{X}$ & \\
\hline & $\begin{array}{l}\text { Mejorar el aprovechamiento de los } \\
\text { subproductos }\end{array}$ & & 8 & $\bar{X}$ \\
\hline & $\begin{array}{l}\text { Mejorar la comercialización a diferentes } \\
\text { escalas (local, nacional, internacional) }\end{array}$ & & $\bar{X}$ & \\
\hline & $\begin{array}{l}\text { Fomentar hábito y cultura de consumo } \\
\text { de miel a nivel local, sensibilizando sobre } \\
\text { importancia de la apicultura }\end{array}$ & & $\mathrm{X}$ & $\mathrm{X}$ \\
\hline \multirow[t]{4}{*}{$\begin{array}{l}\text { Institucional } \\
\text { organizacional }\end{array}$} & $\begin{array}{l}\text { Mejorar la capacidad de organización } \\
\text { gestión y administración de las } \\
\text { organizaciones y grupos de apicultores }\end{array}$ & $\mathrm{X}$ & $\mathrm{X}$ & \\
\hline & $\begin{array}{l}\text { Articular los grupos que trabajan en la } \\
\text { apicultura y Coordinar con las instituciones } \\
\text { del Estado y organismos para que apoyen el } \\
\text { tema de la apicultura en los territorios } \\
\end{array}$ & $\bar{X}$ & $\bar{X}$ & $\bar{X}$ \\
\hline & $\begin{array}{l}\text { Aumentar el financiamiento para el sector } \\
\text { apícola (más fondos, mas financieras...) }\end{array}$ & $\mathrm{X}$ & $\mathrm{X}$ & \\
\hline & $\begin{array}{l}\text { Mejor aprovechamiento del recurso humano } \\
\text { local capacitado a beneficio del desarrollo de } \\
\text { los diferentes grupos apícolas }\end{array}$ & & $\bar{X}$ & \\
\hline
\end{tabular}


El análisis de los elementos mencionados por los actores permite evidenciar los siguientes aspectos:

- Su coherencia con el análisis realizado de la situación de la apicultura en cada territorio. En efecto, si algunos problemas son comunes (aumento de productividad y producción apícola), otros reflejan la especificidad de la problemática del desarrollo de la apicultura en cada territorio:

- En Ciudad Darío es la necesidad estratégica de consolidar el sector apícola integrando nuevos productores, en particular jóvenes, de forma articulada con la mejoría de las condiciones ambientales de la producción apícola. Hay muchos avances logrados por COOPAPIM en conocimientos de procesos de transformación y comercialización, pero se requiere de mayor financiamiento para aumentar su volumen de trabajo.

- En El Sauce, espacio saturado de colmenas, se necesita el ordenamiento del aprovechamiento del espacio, el aumento del potencial florístico a nivel global y de fincas, así como la mejoría del manejo técnico de las colmenas (para más rendimientos) y del aprovechamiento de las colmenas (sub productos, transformación, comercialización...).

- En Boaco existe una gran cantidad de muy pequeños productores con equipamientos insuficientes, tanto ellos como sus organizaciones. Su fortalecimiento a este nivel es clave tanto como el manejo técnico de los apiarios. Adicionalmente, estas organizaciones, muchas de ellas nuevas, requieren procesos de consolidación de sus niveles organizativos internos.

- $\quad$ En todos los territorios se enfatiza la necesidad de un mayor reconocimiento de la apicultura como una actividad económica importante en el territorio y su integración en las instancias y planes de desarrollo territorial, lo que también pasa por la consolidación de los mecanismos de articulación internos del sector apícola en los mismos territorios.

Se solicitó a los participantes identificar las innovaciones claves que se han realizado en los últimos años ('en marcha') o que se están planteando realizar ('en espera') para lograr avanzar hacia este 'progreso' de la apicultura, lográndose identificar de cuatro a ocho innovaciones en cada territorio (cuadro 7). 
Cuadro 7. Innovaciones claves identificadas por los participantes

\begin{tabular}{|c|c|c|c|c|}
\hline Sectores & Innovaciones identificadas & Boaco & El Sauce & $\begin{array}{l}\text { Ciudad } \\
\text { Darío }\end{array}$ \\
\hline \multirow{2}{*}{ Ambiental } & $\begin{array}{l}\text { Integración de nuevos socios a la } \\
\text { organización apícola para facilitar } \\
\text { trashumancia y aprovechamiento de } \\
\text { floración en el territorio }\end{array}$ & & & $\begin{array}{c}\text { En } \\
\text { marcha }\end{array}$ \\
\hline & $\begin{array}{l}\text { Manejo técnico de finca } \\
\text { (diversificación para mejorar } \\
\text { floración) }\end{array}$ & & $\begin{array}{c}\text { En } \\
\text { marcha }\end{array}$ & \\
\hline \multirow{3}{*}{ Producción } & $\begin{array}{l}\text { Renovación de reinas anual o } \\
\text { bianualmente }\end{array}$ & En marcha & En espera & \\
\hline & $\begin{array}{l}\text { Crianza de reinas para la formación } \\
\text { de núcleos }\end{array}$ & En marcha & & \\
\hline & $\begin{array}{l}\text { Eliminación del panal zanganero } \\
\text { para control de la Varroa. }\end{array}$ & & $\begin{array}{c}\text { En } \\
\text { marcha }\end{array}$ & \\
\hline \multirow[t]{4}{*}{$\begin{array}{l}\text { Procesamiento } \\
\text { y comercialización }\end{array}$} & $\begin{array}{l}\text { Fraccionamiento de miel y mercados } \\
\text { alternos }\end{array}$ & En marcha & & \\
\hline & $\begin{array}{l}\text { Acopio de miel a mediana escala } \\
\text { (experimental) para ampliación } \\
\text { posterior }\end{array}$ & En marcha & & \\
\hline & $\begin{array}{l}\text { Transformación de la miel (levanta } \\
\text { muertos, propóleos en tintura, polen } \\
\text { en grano, propóleos, procesamiento } \\
\text { de la cera) }\end{array}$ & & En espera & $\begin{array}{c}\text { En } \\
\text { marcha }\end{array}$ \\
\hline & Centro de documentación y museo & En espera & & \\
\hline \multirow[t]{4}{*}{$\begin{array}{l}\text { Institucional } \\
\text { organizacional }\end{array}$} & $\begin{array}{l}\text { Otorgamiento de crédito apícola } \\
\text { como crédito agropecuario }\end{array}$ & En marcha & $\begin{array}{c}\text { En } \\
\text { marcha }\end{array}$ & \\
\hline & $\begin{array}{l}\text { Organización y/o sensibilización de } \\
\text { grupo de jóvenes apícolas }\end{array}$ & En marcha & & $\begin{array}{c}\text { En } \\
\text { espera }\end{array}$ \\
\hline & Creación de recursos financieros & En espera & & \\
\hline & $\begin{array}{l}\text { Otorgamiento de crédito para } \\
\text { acopio de miel }\end{array}$ & & & $\begin{array}{c}\text { En } \\
\text { marcha }\end{array}$ \\
\hline
\end{tabular}

Las entrevistas posteriores al taller con actores vinculados a las innovaciones en marcha permitieron analizarlas más a profundidad para entender cuáles fueron los elementos claves que las hicieron posibles, obteniendo aprendizajes importantes que fueron compartidos en el taller.

Dentro de los aprendizajes centrales se pueden mencionar los siguientes:

- Las innovaciones son producto de procesos que involucran a un conjunto de actores cuya interacción es clave. Así por ejemplo, en las cuatro innovaciones identificada en Ciudad Darío, participaron un total de 11 actores, entre internos y externos, todos jugando un papel importante en el inicio de la apicultura en el municipio, facilitando acompañamientos, equipamiento, capacitación y/o seguimiento técnico (ilustración 8). 


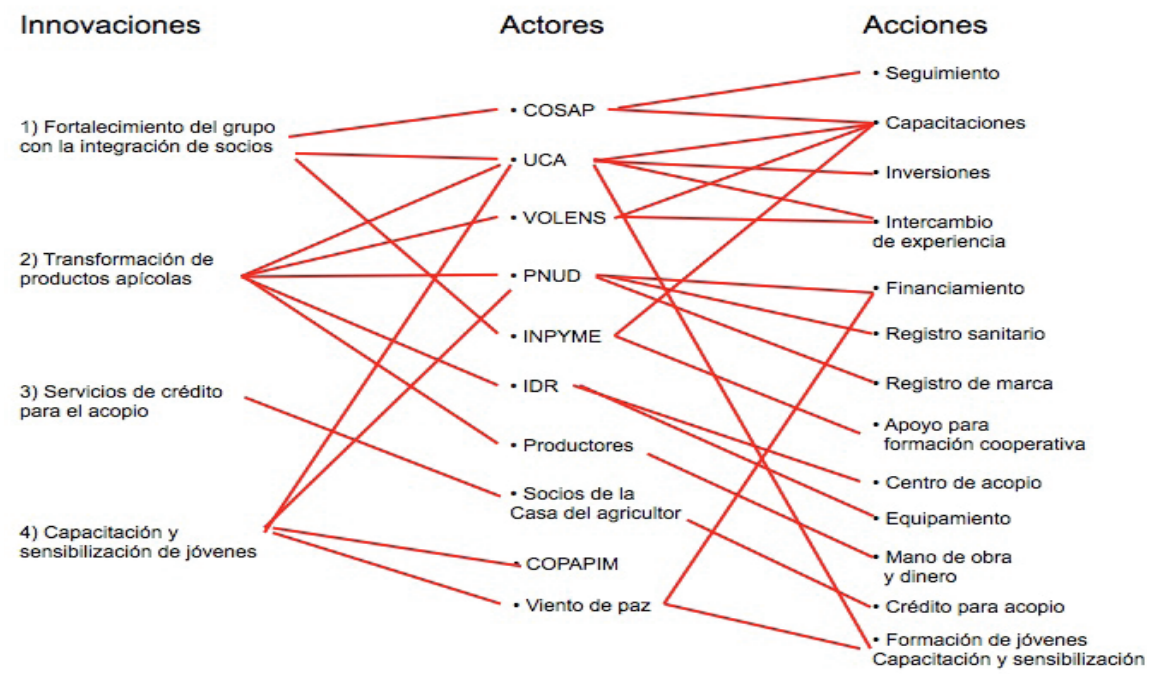

Ilustración 8. Actores e interacciones en los procesos de innovación en Ciudad Darío

Fuente: Ruiz y Trejos (2010).

- Los procesos de innovación constituyen procesos de fortalecimiento de capacidades y cuando son exitosos, permiten proporcionar y difundir mucha confianza en las perspectivas de desarrollo de la apicultura.

- Las innovaciones organizativas pueden ser claves para propiciar innovaciones productivas. Por ejemplo, la integración de socios de diferentes zonas del municipio en la COOPAPIM fue estratégica para practicar la trashumancia entre ellas, aprovechando la gradiente de floración entre diferentes micro cuencas.

- La innovación de un servicio de crédito para acopio de miel permitió evidenciar la posibilidad, aun en la ausencia de sistemas de financiamiento específico, de aprovechar fortalezas locales como la alianza con otro actor local (Casa del Agricultor) para acopiar y luego comercializar con mejores precios incidiendo en el mejoramiento de la generación de ingresos para los apicultores.

Se pudieron identificar también aspectos claves que limitan la difusión de ciertas innovaciones en los territorios:

- La ausencia de tierra propia de los apicultores para mejorar las condiciones ambientales de su finca y aumentar su potencial florístico.

- La falta de equipos, medios o recursos para poner en práctica nuevos conocimientos (renovación de reinas, transformación de productos, etc.).

- La ausencia de actores claves: policías para evitar abigeo en lugares potenciales para la trashumancia, autoridades locales para mayores regulaciones ambientales en el territorio.

- Insuficientes conocimientos sobre biología, ecología, control natural y alimentación natural, por falta de una asistencia técnica adecuada. 


\subsection{Estrategias multi-actores de consolidación del sector (resultados del 3er subestudio)}

El análisis de estos procesos sirvió de base a la identificación de indicadores locales claves para el desarrollo de la apicultura que, una vez validados por los actores locales, permitieron la formulación de estrategias de desarrollo de la apicultura en cada territorio en el 3er taller del proceso. Los indicadores claves fueron agrupados por grandes sectores (cuadro 8).

Cuadro 8. Indicadores locales claves para el desarrollo de la apicultura

\begin{tabular}{|c|c|c|c|c|}
\hline & $\begin{array}{c}\text { Indicadores locales claves } \\
\text { para el desarrollo de la } \\
\text { apicultura }\end{array}$ & Boaco & $\begin{array}{c}\text { El } \\
\text { Sauce }\end{array}$ & $\begin{array}{c}\text { Ciudad } \\
\text { Darío }\end{array}$ \\
\hline \multirow{3}{*}{$\begin{array}{l}\text { Condiciones } \\
\text { ambientales }\end{array}$} & $\begin{array}{l}\text { \% de áreas de pequeños } \\
\text { y medianos productores } \\
\text { destinados a la conservación } \\
\text { del bosque }\end{array}$ & & & $\mathrm{X}$ \\
\hline & $\begin{array}{l}\text { Número de productores } \\
\text { implementando planes de } \\
\text { manejo de fincas para el manejo } \\
\text { y conservación del recurso } \\
\text { forestal melífero }\end{array}$ & & $\mathrm{X}$ & \\
\hline & $\begin{array}{l}\text { Distribución de las colmenas } \\
\text { en el territorio en función del } \\
\text { potencial florístico }\end{array}$ & & $\mathrm{X}$ & \\
\hline \multirow{7}{*}{ Producción } & $\begin{array}{l}\text { Número de apicultores en el } \\
\text { territorio }\end{array}$ & & & $\mathrm{X}$ \\
\hline & $\begin{array}{l}\text { Número de comunidades } \\
\text { integrando jóvenes en temas } \\
\text { de manejo de bosque y manejo } \\
\text { apícola }\end{array}$ & & & $\mathrm{X}$ \\
\hline & $\begin{array}{l}\text { Número de colmenas por } \\
\text { apicultor }\end{array}$ & $\mathrm{X}$ & $\mathrm{X}$ & $\mathrm{X}$ \\
\hline & Número de kg/colmena/ciclo & $\mathrm{X}$ & $\mathrm{X}$ & $\mathrm{X}$ \\
\hline & $\begin{array}{l}\text { Número de cooperativas con } \\
\text { planes de manejo técnico de los } \\
\text { apiarios de sus socios }\end{array}$ & $\mathrm{X}$ & & \\
\hline & $\begin{array}{l}\text { Número de productores que } \\
\text { reciben asistencia técnica } \\
\text { dirigida para mejorar el manejo } \\
\text { de sus apiarios y la calidad de } \\
\text { la miel }\end{array}$ & & $\mathrm{X}$ & \\
\hline & $\begin{array}{l}\text { Número de familias que } \\
\text { aumentan en número y } \\
\text { porcentaje sus ingresos }\end{array}$ & $\mathrm{X}$ & & \\
\hline
\end{tabular}




\begin{tabular}{|c|c|c|c|c|}
\hline \multirow{8}{*}{$\begin{array}{l}\text { Procesamiento y } \\
\text { comercialización }\end{array}$} & $\begin{array}{l}\text { Cantidades de organizaciones } \\
\text { que realizan procesos de } \\
\text { fraccionamiento de la miel }\end{array}$ & $X$ & & \\
\hline & $\begin{array}{l}\% \text { de productores con } \\
\text { producción de miel certificada }\end{array}$ & & $X$ & \\
\hline & $\begin{array}{l}\text { Cantidad de grupos equipados } \\
\text { con equipos de extracción de } \\
\text { miel (de buena calidad) }\end{array}$ & $X$ & & \\
\hline & $\begin{array}{l}\% \text { de productores sacando sub } \\
\text { productos de la colmena }\end{array}$ & & $X$ & \\
\hline & $\begin{array}{l}\text { Cantidad de organizaciones con } \\
\text { condiciones y capacidades de } \\
\text { acopio en el territorio }\end{array}$ & $\mathrm{X}$ & & \\
\hline & $\begin{array}{l}\text { \% de la producción colocada } \\
\text { directamente en el mercado } \\
\text { internacional }\end{array}$ & & $X$ & \\
\hline & $\begin{array}{l}\text { Grado de sensibilización } \\
\text { de la población del dpto. de } \\
\text { Boaco (sobre la importancia } \\
\text { económica, social y ambiental } \\
\text { de la apicultura y la miel) }\end{array}$ & $X$ & & \\
\hline & $\begin{array}{l}\text { Número de gramos consumidos } \\
\text { per cápita en el territorio }\end{array}$ & & & $X$ \\
\hline \multirow{6}{*}{$\begin{array}{l}\text { Organizacional - } \\
\text { institucional }\end{array}$} & $\begin{array}{l}\text { Cantidad de cooperativas y } \\
\text { grupos que consolidan su } \\
\text { funcionamiento interno }\end{array}$ & $X$ & & \\
\hline & $\begin{array}{l}\text { Existencia de estructura } \\
\text { organizativa de los apicultores } \\
\text { a nivel local y su participación } \\
\text { en GPC }\end{array}$ & & $X$ & \\
\hline & $\begin{array}{l}\text { Existencia de una estrategia de } \\
\text { sostenibilidad de la explotación } \\
\text { apícola integrada en planes de } \\
\text { desarrollo municipales }\end{array}$ & & $X$ & \\
\hline & $\begin{array}{l}\text { Existencia de la apicultura } \\
\text { en las comisiones y planes } \\
\text { municipales }\end{array}$ & & & $X$ \\
\hline & $\begin{array}{l}\text { Número de micro-financieras } \\
\text { con líneas de crédito para el } \\
\text { sector apícola }\end{array}$ & $X$ & & \\
\hline & $\begin{array}{l}\text { Número de productores } \\
\text { que acceden a crédito para } \\
\text { apicultura }\end{array}$ & $X$ & $X$ & \\
\hline
\end{tabular}


El análisis de los indicadores propuestos por los actores permite evidenciar su coherencia con los aspectos claves identificados para el desarrollo de la apicultura (cuadro 6) y su carácter efectivamente local: aunque algunos se refieren a las mismas variables, su formulación precisa responde al contexto local específico en el cual fueron formulados.

Finalmente, este taller permitió a los actores formular estrategias de desarrollo desde cada uno de estos indicadores con tres pasos:

- definición de la meta: el nivel que se espera lograr del indicador a mediano plazo, siendo realistas desde las posibilidades y oportunidades existentes actualmente o el alcance de los actores locales

- valoración del nivel actual del indicador

- definición de acciones estratégicas a impulsar por los actores para lograr la meta planteada tomando en cuenta el punto de partida, así como el conjunto de los análisis realizados, en particular vinculados a las innovaciones.

A manera de ejemplo se presentan los resultados de este proceso para algunos indicadores claves en el caso de El Sauce (cuadro 9).

Cuadro 9. Ejemplos de estrategias formuladas en El Sauce

\begin{tabular}{|l|l|l|l|}
\hline \multicolumn{1}{|c|}{ Indicador } & \multicolumn{1}{|c|}{ Meta } & Estado actual & \multicolumn{1}{c|}{ Estrategia } \\
\hline $\begin{array}{l}\text { Distribución } \\
\text { de las } \\
\text { colmenas en } \\
\text { el territorio } \\
\text { en función } \\
\text { del potencial } \\
\text { florístico }\end{array}$ & $\begin{array}{l}\text { Lograr mayor } \\
\text { equilibrio en la } \\
\text { distribución de } \\
\text { colmenas en el } \\
\text { territorio en función } \\
\text { del potencial } \\
\text { florístico }\end{array}$ & $\begin{array}{l}\text { Existe } \\
\text { saturación } \\
\text { y sobre } \\
\text { explotación } \\
\text { del potencial } \\
\text { florístico } \\
\text { existente en El } \\
\text { Sauce }\end{array}$ & $\begin{array}{l}\text { Desarrollar un estudio floristico y } \\
\text { un mapa apícola municipal en El } \\
\text { Sauce. } \\
\text { Implementación del Plan de } \\
\text { Ordenamiento de Desarrollo } \\
\text { Municipal con líneas estratégicas } \\
\text { de uso de suelo para la apicultura } \\
\text { y reforestación y recomendaciones } \\
\text { hacia productores. }\end{array}$ \\
\hline $\begin{array}{l}\text { Número de } \\
\text { kgs de miel/ } \\
\text { colmena / } \\
\text { ciclo }\end{array}$ & $\begin{array}{l}\text { Aumentar los } \\
\text { rendimientos por } \\
\text { colmena en 40 kilos } \\
\text { por ciclo }\end{array}$ & $\begin{array}{l}\text { 20 a 30 kilos } \\
\text { por colmena }\end{array}$ & $\begin{array}{l}\text { Implementación de buenas prácticas } \\
\text { apícolas a través del cuido y } \\
\text { protección del medio ambiente. } \\
\text { Venta de los productos de acuerdo a } \\
\text { la demanda del mercado. }\end{array}$ \\
\hline $\begin{array}{l}\text { Existencia } \\
\text { de estructura } \\
\text { organizativa } \\
\text { de los } \\
\text { apicultores a } \\
\text { nivel local y su } \\
\text { participación } \\
\text { en el GPC }\end{array}$ & $\begin{array}{l}\text { Las organizaciones } \\
\text { apícolas articuladas } \\
\text { con organizaciones e } \\
\text { instituciones locales, } \\
\text { conforman una } \\
\text { instancia organizativa } \\
\text { local que vela por el } \\
\text { buen desarrollo de } \\
\text { la apicultura en El } \\
\text { Sauce y participa en } \\
\text { el GPC }\end{array}$ & $\begin{array}{l}\text { Los apicultores } \\
\text { no están } \\
\text { articulados } \\
\text { en una sola } \\
\text { instancia e } \\
\text { integrados en } \\
\text { la estructura de } \\
\text { los GPC en el } \\
\text { municipio }\end{array}$ & $\begin{array}{l}\text { Funcionamiento eficiente de } \\
\text { una estructura organizativa de } \\
\text { apicultores de El Sauce por medio } \\
\text { del fortalecimiento organizativo e } \\
\text { integración de representantes de la } \\
\text { estructura de apicultores en el GPC. }\end{array}$ \\
\end{tabular}




\begin{tabular}{|l|l|l|l|}
\hline $\begin{array}{l}\text { Número de } \\
\text { productores } \\
\text { que reciben } \\
\text { asistencia } \\
\text { técnica } \\
\text { dirigida para } \\
\text { mejorar el } \\
\text { manejo de } \\
\text { sus apiarios } \\
\text { y la calidad } \\
\text { de la miel } \\
\text { asistencia técnica para } \\
\text { mejorar el manejo de } \\
\text { apiarios }\end{array}$ & $\begin{array}{l}\text { Los } \\
\text { productores y } \\
\text { productoras } \\
\text { no cuentan } \\
\text { con asistencia } \\
\text { técnica dirigida } \\
\text { para el manejo } \\
\text { de sus apiarios }\end{array}$ & $\begin{array}{l}\text { Las organizaciones apícolas } \\
\text { articuladas con instituciones locales } \\
\text { implementan un plan de asistencia } \\
\text { técnicantrol de calidad de miel) } \\
\text { locales. }\end{array}$ \\
\hline $\begin{array}{l}\text { Número de } \\
\text { productores } \\
\text { que acceden a } \\
\text { créditos para } \\
\text { el desarrollo } \\
\text { de sus apiarios }\end{array}$ & $\begin{array}{l}\text { Los productores } \\
\text { apícolas acceden a } \\
\text { fondos de crédito } \\
\text { para el desarrollo de } \\
\text { sus apiarios }\end{array}$ & $\begin{array}{l}\text { Pocos } \\
\text { apicultores } \\
\text { acceden a } \\
\text { crédito }\end{array}$ & $\begin{array}{l}\text { Las organizaciones formales tienen } \\
\text { programas y carteras de crédito } \\
\text { accesibles para los productores y } \\
\text { productoras de El Sauce. } \\
\text { El FDL y FUDMU dan crédito } \\
\text { pero los mecanismos son poco } \\
\text { conocido por los/las productores/ } \\
\text { as, por lo que se van a promocionar. }\end{array}$ \\
\hline
\end{tabular}

Fuente: Peña y Obregón (2011).

\section{Conclusiones y recomendaciones}

Se ha identificado en cada territorio un gran número de actores relacionados con la actividad apícola con presencia directa a nivel municipal, sus principales características e interrelaciones, y se han agrupado en cinco grandes categorías según sus funciones en relación al desarrollo de la actividad apícola: productores de miel, organizaciones y servicios de apoyo al desarrollo de la apicultura, reguladores de la actividad apícola, proveedores de materiales, insumos y servicios, y actores vinculados al proceso de comercialización de la miel.

El sector productivo apícola está principalmente en manos de pequeños productores que lo consideran como un rubro efectivo de diversificación productiva y presentan un nivel fuerte de organización a nivel local, ya que en los tres territorios la gran mayoría de los productores están organizados.

Se puede observar una correlación clara entre el grado de organización de los apicultores y el nivel de desarrollo de la actividad apícola. Los apicultores afiliados a cooperativas cuentan globalmente con más colmenas y mejores niveles de rendimientos que los productores pertenecientes a grupos informales o individuales. Por ende, se evidencia que las organizaciones de apicultores juegan un papel muy importante en el desarrollo de la apicultura en su territorio, articulando los diferentes servicios y actores de apoyo a la apicultura.

Aun si en los diferentes territorios la venta directa en mercados localestradicionales no deja de tener su importancia, estas organizaciones juegan un papel clave para facilitar a los apicultores el acceso a mercados más remuneradores (tiendas naturistas, supermercados, exportación de miel certificada) pero con requerimientos que por sí solos no podrían cumplir. 
Existen rasgos comunes en las dinámicas de la apicultura en los tres territorios que determinan algunas necesidades estratégicas compartidas: crecimiento del número de apicultores y de colmenas con la creación de muchas capacidades locales, pero con una disminución de rendimientos productivos que les plantean como retos comunes el aumento de la productividad y producción apícola.

Cada territorio presenta también sus especificidades que se deben tomar en cuenta al momento de formular estrategias de desarrollo del sector:

- $\quad$ En El Sauce se da una saturación del espacio por el aumento de la cantidad de apicultores y colmenas, lo cual les obliga a aumentar la práctica de trashumancia sobre distancias más largas y por ende con costos más altos que disminuyen la rentabilidad de la actividad. Son claves el ordenamiento del aprovechamiento del espacio, y el aumento del potencial florístico a nivel global y de fincas.

- En Boaco el aumento de la apicultura consistió en gran parte en el crecimiento de la cantidad de pequeños apicultores sin que tengan ellos, ni sus organizaciones, el equipamiento necesario, dándose una disminución de rendimientos y calidad de la miel. Las organizaciones, muchas de ellas nuevas, requieren también de procesos internos de consolidación.

- $\quad$ En Ciudad Darío se ha logrado fortalecer capacidades técnicas, organizativas y administrativas pero a una escala muy reducida y aún insuficiente para que tenga un peso real en la dinámica del territorio, principalmente por falta de recursos financieros para dar saltos. Existe una necesidad estratégica de consolidar el sector apícola integrando nuevos productores -en particular jóvenes- a esta actividad de forma articulada con la mejoría de las condiciones ambientales de la producción apícola.

Se ha logrado identificar, de forma participativa, en cada territorio, de cuatro a ocho innovaciones claves que se han realizado en los últimos años ('en marcha') o que los actores se están planteando realizar ('en espera') para lograr un 'progreso' de la apicultura. El análisis de estas innovaciones permitió obtener y socializar aprendizajes muy importantes a la hora de formular indicadores locales claves y luego estrategias de desarrollo del sector.

Finalmente se logró formular de manera concertada un conjunto de acciones estratégicas para el desarrollo de la apicultura en cada territorio con sus indicadores y metas, los cuales deberían de constituir referencias importantes para acciones futuras.

\section{Agradecimientos}

Agradezco a la Universidad Centroamericana que ha financiado este estudio por medio de sus Fondos Concursables de la Agenda I+D+I, así como a los investigadores que han colaborado con este estudio, articulando esfuerzos desde distintas instancias de la UCA: Área de Desarrollo Agrario y Rural (Ricardo Ruiz, Eddy Trejos), Maestría en Desarrollo Rural (Felix Pavón, Marlon Rojas, Elena Peña, Esmilse Obregón y Falguni Guharay), Facultad de Ciencias Económicas y Empresariales (Juan Carlos Polvorosa) y Nitlapán (Selmira Flores). 


\section{Referencias bibliográficas}

Arce A. \& Long, N. (1988). La dinámica de las interfaces de conocimiento entre los burócratas agrarios y los campesinos: un estudio de caso jalisciense. Cuadernos (8), 3-23. México: Universidad de Guadalajara.

Chavarría, H. \& Sepúlveda, S. (2001). Factores no económicos de la competitividad, Serie Cuadernos Técnicos / IICA, (18). San José, C. R.: IICA.

Darré, J. P. (1989). Le rôle des groupes de voisinage dans l'élaboration et la reproduction des normes de travail. Paris : B.T.I. n 442/443, pp. 353-358.

Darré, J. P. (1994). Pairs et experts dans l'agriculture. Dialogues et production de connaissance pour l'action. Technologies Idéologies Pratiques, XII (1). Ed. érès.

Dietsch, L. (2002). Caracterización Agrosocioeconómica de la zona seca de Nicaragua. Managua: UCA-ADAA.

Dietsch, L., Ruault, C. \& Touzard, J. M. (2008). Propuestas para un programa de investigación - acción al servicio del desarrollo rural. Informe final del taller Implementación de un programa de investigación. Managua, UCA-ADAA, GERDAL, UMR Innovation (manuscrito no publicado).

Engel, P.G.H. \& Salomon, M.L. (1997) Facilitating innovation for development: a RAAKS resource box. Amsterdam: KITCTA/STOAS.

Guharay, F., Villar, L. \& González, M. (2010). Familias rurales mejorando la productividad y la calidad de sus cafés. Managua: EDISA.

Garibay, S. \& Zamora, E. (2003). Producción orgánica en Nicaragua: limitaciones y Potencialidades. Managua: SIMAS

INPYME. (2005). Diagnóstico de necesidades de transferencia tecnológica de las MIPYME apicolas. Managua: INPYME.

MAGFOR. (2006). Censo Nacional Apícola. Managua: MAGFOR.

Pavón, F. \& Rojas, M. (2011). Estrategias de consolidación de la producción y acceso a mercados de pequeñas/os productores apícolas de las zonas secas de Boaco, mediante procesos multi-actores. Tesis de Maestría no publicada, Universidad Centroamericana, Managua, Nicaragua.

Peña, E. \& Obregón, E. (2011). Estrategias de consolidación de la producción y acceso a mercados de pequeñas/os productores apícolas de las zonas secas de El Sauce, mediante procesos multi-actores. Tesis de Maestría no publicada, Universidad Centroamericana, Managua, Nicaragua.

Ruiz, R. \& Trejos, E. (2010). Estrategia de Desarrollo Apícola para el municipio de Ciudad Darío. Managua: UCA-ADAA.

Schetjman, A. \& Berdegué, J. (2003). Desarrollo Territorial rural. Santiago de Chile: RIMISP 